NBER WORKING PAPER SERIES

PANDEMICS THROUGH THE LENS OF OCCUPATIONS

\author{
Anand Chopra \\ Michael B. Devereux \\ Amartya Lahiri \\ Working Paper 27841 \\ http://www.nber.org/papers/w27841 \\ NATIONAL BUREAU OF ECONOMIC RESEARCH \\ 1050 Massachusetts Avenue \\ Cambridge, MA 02138 \\ September 2020
}

We are grateful for comments from seminar participants at the Bank of Canada, the Vancouver School of Economics, and the Government of British Columbia. Devereux and Lahiri thank SSHRC for financial support. The views expressed herein are those of the authors and do not necessarily reflect the views of the National Bureau of Economic Research.

NBER working papers are circulated for discussion and comment purposes. They have not been peer-reviewed or been subject to the review by the NBER Board of Directors that accompanies official NBER publications.

(C) 2020 by Anand Chopra, Michael B. Devereux, and Amartya Lahiri. All rights reserved. Short sections of text, not to exceed two paragraphs, may be quoted without explicit permission provided that full credit, including $\odot$ notice, is given to the source. 
Pandemics Through the Lens of Occupations

Anand Chopra, Michael B. Devereux, and Amartya Lahiri

NBER Working Paper No. 27841

September 2020

JEL No. E0,I0

\begin{abstract}
$\underline{\text { ABSTRACT }}$
We outline a macro-pandemic model where individuals can select into working from home or in the market. Market work increases the risk of infection. Occupations differ in the ease of substitution between market and home work, and in the risk of infection. We examine the evolution of a pandemic in the model as well as its macroeconomic and distributional consequences. The model is calibrated to British Columbian data to examine the implications of shutting down different industries by linking industries to occupations. We find that endogenous choice to selfisolate is key: it reduces the peak infection rate by 2 percentage points but reduces the trough consumption level by 4 percentage points, even without policy mandated lockdowns. The model also produces widening consumption inequality, a fact that has characterized COVID-19.

Anand Chopra

University of British Columbia

anandchopra13@gmail.com

Michael B. Devereux

Department of Economics

University of British Columbia

997-1873 East Mall

Vancouver, BC V6T 1Z1

CANADA

and NBER

mbdevereux@gmail.com

Amartya Lahiri

Vancouver School of Economics

University of British Columbia

6000 Iona Drive

Vancouver, BC V6T 1Z1

CANADA

amartyalahiri@gmail.com
\end{abstract}




\title{
Pandemics Through the Lens of Occupations
}

\author{
Anand Chopra \\ Michael B. Devereux \\ Amartya Lahiri \\ $\mathrm{UBC}$ \\ UBC and NBER \\ UBC \\ anandchopra13@gmail.com \\ michael.devereux@ubc.ca \\ amartya.lahiri@ubc.ca
}

August 31, 2020

\begin{abstract}
We outline a macro-pandemic model where individuals can select into working from home or in the market. Market work increases the risk of infection. Occupations differ in the ease of substitution between market and home work, and in the risk of infection. We examine the evolution of a pandemic in the model as well as its macroeconomic and distributional consequences. The model is calibrated to British Columbian data to examine the implications of shutting down different industries by linking industries to occupations. We find that endogenous choice to selfisolate is key: it reduces the peak infection rate by 2 percentage points but reduces the trough consumption level by 4 percentage points, even without policy mandated lockdowns. The model also produces widening consumption inequality, a fact that has characterized COVID-19.
\end{abstract}

\section{Introduction}

As the coronavirus and the disease it spawns, COVID-19, has spread across the globe, it has unleashed fearsome challenges for epidemiologists, public health professionals, economists and public policy officials to both understand and devise methods to arrest its spread and attenuate its effects. The particular challenge in managing the crisis is the tradeoff between the public health and economic costs of the disease.

In this paper we formalize a macroeconomic model and blend it with the standard SIR model for pandemics. Relative to standard macroeconomic models, our structure has two main innovations. First, we conceptualize aggregate output as being the outcome of the labour effort of different 
occupations. We believe this focus is important since a significant source of contagion of infections is the interaction of people while working. However, labour is supplied through many different occupations with different degrees of required social proximity and interaction. Hence, the economic costs of pandemics are likely to vary significantly with different occupation mixes in society.

A second innovation of the model is that it allows individuals to choose whether to work from the market or work from home. The ease with which individuals can substitute into working from home varies across occupations. Our model and empirical implementation incorporates this variation. Allowing individuals to choose the location of their work allows them to self-insure against infection risk. This appears to be a key decision facing private agents and policymakers alike as they decide on the methods of dealing with the crisis.

Our model is calibrated to British Columbian occupation and labour force data from the Canadian Census 2016. We show that the endogeneity of market participation is quantitatively important with the peak infection rate lower by 2 percentage points. Risk aversion is the key driver for this result. Moreover, the effect of lockdowns and their relaxation is also significantly impacted by the endogeneity of market participation. Lockdowns that are relaxed while infections are still growing result in slower recoveries as individuals endogenously choose to stay away from market work, even without coercion.

We conduct a number of robustness checks on our results. We uncover three important insights from these exercises. First, our baseline model assumes a common infection risk from market work for all occupations. Relaxing this assumption and allowing for occupation specific infection risk from market work does not change the baseline results by much. Second, the degree of risk aversion is very important. With risk-neutrality, the difference between endogenous and exogenous choices of work location almost disappears. Third, the productivity of individuals contingent on becoming infected is important. The lower the productivity of the infected, the lower is the peak of the overall infection rate.

The structure that we formalize also has distributional implications. Since individual skills are occupation specific and occupations have different degrees of substitutability between market and home work, a pandemic induces heterogeneity in infection rates and consumption across occupations. Occupations which are easy to perform from home without significant loss of income allow individuals to insulate themselves from infection risk without sacrificing consumption. Contrarily, 
occupations that are harder to perform from home see higher infections and lower consumption.

The model matches the data fact that the higher the income group the greater the initial drop in consumption and the slower the consumption recovery. The model also predicts that the trough of consumption of the lowest income groups comes much later than for relatively richer groups. Hence, we may not have seen the worst yet in terms of the distributional consequences of COVID-19.

We believe our results point to the importance of public health initiatives that prioritize building societal confidence in the safety of market work. One such measure is widespread and frequent testing of the general population. Absent such measures, economic recovery from COVID-19 may be prolonged, possibly until the commercial development of an effective vaccine.

Since the beginning of the global Covid-19 pandemic, there has been an explosion of research studies analyzing the links between macroeconomic and epidemiological models. The work has been so prolific that already there are a already number of reviews of the recent literature (Brodeur et al. (2020), Hur and Jenuwine (2020)) We do not attempt here to provide a complete summary of new papers in this area. Our paper is closest on the economic side to Eichenbaum et al. (2020), and takes its calibration of disease dynamics from Atkeson (2020). Recent work in Chetty et al. (2020) documents the evolution of inequality along various margins in the aftermath of COVID-19. We use the consumption inequality facts presented in their work as a benchmark to compare the distributional dynamics of our model.

Other papers closely related to ours are Dingel and Neiman (2020), who construct a measure of ease of home work by occupation from ONET data. We use a measure similar to theirs to benchmark our simulations. Theoretical models that have some relation to ours, besides Eichenbaum et al. (2020), mentioned above, are Krueger et al. (2020), Jones et al. (2020), and Bodenstein et al. (2020). Acemoglu et al. (2020), Alvarez et al. (2020), and Jones et al. (2020) conduct optimal policy experiments in richly parameterized SIR models. The message of our paper, that endogenous adjustment by individuals accounts for a substantial part of the response to pandemic risk, beyond official lockdowns, is also stressed in an empirical study by Goolsbee and Syverson (2020).

The next section presents the model while Section 3 describes the dynamics of a pandemic and some theoretical results. Section 4 describes the calibration of the model and the quantitative results. Section 5 explores the robustness of the quantitative results with respect to key parameters while Section 6 compares the distributional predictions of the model with those in the data. The 
last section concludes.

\section{Model}

We study a closed economy with a continuum of occupations with measure one. The economy consumes a final good that is produced by multiple sectors. Sectoral goods are produced by combining various occupations. Within each occupation $i$, there is a population $L_{t}(i)$ of individuals at date $t$. Hence, the total population is $L_{t}=\int_{0}^{1} L_{t}(i) d i$.

Infinitely lived individuals in the economy have one unit of labour time that they supply inelastically to work every period. Individuals have occupation specific skills. These skills can be used to supply work effort from home or the market. A representative individual within occupation $i$ receives wage $w^{h}(i)$ from working at home and wage $w^{m}(i)$ from working in the market. Labour markets are competitive so that wages reflect the marginal products of labour from home and market work in each occupation. Note that for some occupations, the value of work from home may be extremely small or close to zero. Our model allows for arbitrarily small values of $w^{h}$ for some occupations.

We assume that occupations are arranged in order of the wage from working in the market

relative to working from home. Thus $\frac{w^{m}(j)}{w^{h}(j)}>\frac{w^{m}(i)}{w^{h}(i)}$ for $j>i$. An individual within each occupation will work in the marketplace if the value of market work $V^{m}(i)$ exceeds the value of home work $V^{h}(i)$. So if occupation $i$ decides to work in the marketplace, then occupation $j>i$ will also work in the marketplace. We denote $\theta$ as the share of occupations working in the market rather than home. Thus, defining $\bar{i}$ as the marginal occupation that is indifferent between home and market work, $\theta=1-\bar{i}$.

Individuals maximize the present discounted value of lifetime utility. Thus, an individual $j$ in occupation $i$ maximizes

$$
V^{j}(i, t)=\sum_{t}^{\infty} \ln c_{t}^{j}(i)
$$

Individuals are hand-to-mouth consumers so that every period they consume their current period earnings completely: $c_{t}^{j}(i)=w_{t}(i)$

The epidemiological structure of the model is very similar to recent papers noted above. At every date, within each occupation, there are potentially three types of agents in the economy: 
Susceptible $(S)$, Infected $(I)$, or Recovered $(R)$ with the total population being $L_{t}=S_{t}+I_{t}+R_{t}$. The measure of agents in each of these groups changes over time as a function of the cumulated decisions made by individuals regarding home versus market work, as well as through infections occurring through consumption activities as well as random infections, as described more fully below. In the following we shall use the notation $K_{t}(i)$ to denote the measure of people of type $K=S, I, R$ in occupation $i$ at date $t$.

For an individual, working in the market entails the risk of becoming infected by a virus. This risk is a function of the interaction between infected people and susceptible individuals working in the market. Once infected, individuals either continue to remain infected or recover with probability $\pi_{R}$ or die with probability $\pi_{D}$.

\subsection{Production}

The production structure of the economy consists of a final good that is produced by combining a set of J-intermediate goods corresponding to different sectors. The final good is the numeraire for the model. The final goods technology is

$$
Y_{t}=\left[\sum_{j=1}^{J} \eta^{j(1-\rho)}\left(Y_{t}^{j}\right)^{\rho}\right]^{\frac{1}{\rho}}
$$

where $\rho \leq 1$ controls the elasticity of substitution between sectoral goods and $\sum_{j} \eta^{j}=1$ is assumed.

$Y_{t}^{j}$ denotes output of sector $j$ used by the final goods sector at date $t$. Using $P_{t}^{j}$ to denote the price of sector-j goods, we can derive the demand function for sector-j goods as

$$
Y_{t}^{j}=Y_{t} \eta^{j} P_{t}^{j \frac{1}{\rho-1}}
$$

Equation 4 can be used to derive the price of the basket of final goods, which is unity, as it is the numeraire:

$$
\sum_{j=1}^{J} \eta^{j} P_{t}^{j \frac{\rho}{\rho-1}}=1
$$

In the special case where sectoral goods are perfect substitutes in producing the final good, or $\rho=1$, all sectoral prices must be equal and therefore: $P_{t}^{j}=1$ 
Output for each sector produced by combining the effective labour supply by the continuum of occupations. This labour supply is adjusted for occupation specific productivity, as we shall describe below. The sector $j$ technology is given by

$$
Y_{t}^{j}=\left[\int_{i=0}^{1} \delta^{j}(i)^{\left(1-\rho^{j}\right)}\left(L_{t}^{j}(i)\right)^{\rho^{j}} d i\right]^{\frac{1}{\rho^{j}}}, \rho^{j} \leq 1
$$

Here, labour usage $L_{t}^{j}(i)$ is defined over a continuum of occupations $i$, and $\rho^{j} \leq 1$ controls the elasticity of substitution between occupations in sector-j. $\rho^{j}=1$ is the case of perfect substitutability while $\rho^{j}=-\infty$ is the Leontief case of no substitutability between occupations. $\delta^{j}(i)^{\left(1-\rho^{j}\right)}$ denotes the input weight of occupation $i$ in sector $j$, and we assume that $\int_{0}^{1} \delta^{j}(i) d i=1$. Since both $\rho^{j}$ and $\delta^{j}(i)^{\left(1-\rho^{j}\right)}$ are indexed by $j$, our specification allows the occupational intensity of labour to vary across sectors. ${ }^{1}$

The demand by sector $j$ for labour of occupation $i$ is

$$
L_{t}^{j}(i)=Y_{t}^{j} \delta^{j}(i)\left(\frac{P_{t}(i)}{P_{t}^{j}}\right)^{\frac{1}{\rho^{j}-1}}
$$

where $P_{t}(i)$ represents the price of occupation $i$ good It is straightforward to check from equation (5) that the price of sector-j output is

$$
P_{t}^{j}=\left[\int_{i=0}^{1} \delta^{j}(i) P_{t}(i)^{\frac{\rho^{j}}{\rho^{j}-1}} d i\right]^{\frac{\rho^{j}-1}{\rho^{j}}}
$$

Labour of occupation $i$ is produced by using the linear technology:

$$
\begin{aligned}
L_{t}(i)=A_{i}^{m} & \left\{S_{t}^{m}(i)+R_{t}^{m}(i)+\gamma_{I}^{m} I_{t}^{m}(i)\right\} \\
+ & A_{i}^{h}\left\{S_{t}^{h}(i)+R_{t}^{h}(i)+\gamma_{I}^{h} I_{t}^{h}(i)\right\}
\end{aligned}
$$

where $S^{k}(i), R^{k}(i)$ and $I^{k}(i)$ denote the measures of susceptible, recovered and infected individuals, respectively, in occupation $i$ who are working in $k=h, m$. Note that $h$ denotes home and $m$ denotes market. The productivity of occupation $i$ working from home or market is denoted by $A_{i}^{k}$. We

\footnotetext{
${ }^{1}$ In subsequent analysis, we can allow for sectoral use of other sector's output as part of the production technology, thereby allowing for intermediate input usage in gross production. This can allow us to incorporate different sectoral centrality measures in that analysis of alternative lockdown policies.
} 
assume throughout that $\gamma_{I}^{k}<1$ for $k=h, m$, so that the productivity of infected individuals is strictly less than non-infected workers in every occupation. The productivity terms are not indexed by the time subscript $t$ indicating the assumption that productivity is constant. ${ }^{2}$

In addition, we allow for a tax rate on market work equal to $\tau_{m}$. This tax may be rebated to each affected occupation as a lump-sum rebate, although we also allow for the tax as a pure deadweight cost. We think of this parameter as controlling a policy of health-driven shutdowns in market activity.

Competitive labour markets then imply that wage rates for market and home work are given by

$$
\begin{aligned}
& w^{m}(i, t)=\left(1-\tau^{m}\right) P_{t}(i) A_{i}^{m}, \\
& w^{h}(i, t)=P_{t}(i) A_{i}^{h}, \\
& w_{I}^{m}(i, t)=\left(1-\tau^{m}\right) P_{t}(i) \gamma_{I}^{m} A_{i}^{m}, \\
& w_{I}^{h}(i, t)=P_{t}(i) \gamma_{I}^{h} A_{i}^{h}
\end{aligned}
$$

These conditions determine the after-tax wages in each occupation $i$ for all groups of individuals. Wages in every occupation are constant over time here because both occupational productivity and prices are constant, and assuming also that taxes are constant.

\subsection{The Pre-Infection Economy}

Take an initial situation where there is no risk of being infected in the marketplace. We also assume that there is no tax on market labour during this period. Then

$$
\begin{aligned}
V^{h}(i, t) & =\ln w^{h}(i)+\beta V^{h}(i, t+1)=\frac{\ln w^{h}(i)}{1-\beta} \\
V^{m}(i, t) & =\ln w^{m}(i)+\beta V^{m}(i, t+1)=\frac{\ln w^{m}(i)}{1-\beta}
\end{aligned}
$$

where the second equality in both equations above follow from the fact that since there are no shocks in this economy and there are no sticky variables that evolve gradually over time, wages have to be constant over time. With all other exogenous variables being constant, in each occupation the

\footnotetext{
${ }^{2}$ It is straightforward to allow for exogenous productivity growth in the model.
} 
choice between home and market work depends only on the wage comparison $w^{m}(i)-w^{h}(i)$. Since this is constant, the choice between home and market work remains unchanged over time in every occupation $i$. Thus, an occupation that is performed from home today yields a lifetime utility of $\frac{\ln w^{k}(i)}{1-\beta}$ for $k=h, m$.

There is a cutoff occupation $\bar{i}$ that is determined by the condition $V^{h}(\bar{i})=V^{m}(\bar{i})$. From the expressions for the value functions derived above, the cutoff condition reduces to $w^{h}(\bar{i})=w^{m}(\bar{i})$. All occupations for which $i>\bar{i}$ will be performed through market works while those below the threshold occupation will work from home. The threshold then determines the total number of individuals working in the marketplace as $L^{m}=L-\int_{0}^{\bar{i}} L(i) d i$. The cutoff and the distribution of market versus homework remains unchanged over time.

Occupational output produced by occupation $i$ is given by

$$
L(i)= \begin{cases}L_{0}(i) A_{i}^{h} & \text { if } i<\bar{i} \\ L_{0}(i) A_{i}^{m} & \text { if } i \geq \bar{i}\end{cases}
$$

where $L_{0}(i)$ is the measure of individuals in occupation $i$, which is constant over time absent any pandemic dynamics.

Sectoral output, which is produced by combining occupations, is given by

$$
Y^{j}=\left[\int_{i=0}^{\bar{i}} \delta^{j}(i)^{1-\rho^{j}} L^{j, h}(i)^{\rho^{j}} d i+\int_{i=\bar{i}}^{1} \delta^{j}(i)^{1-\rho^{j}} L^{j, m}(i)^{\rho^{j}} d i\right]^{\frac{1}{\rho^{j}}}, j=1, \ldots, J
$$

Note that all sectoral outputs remain constant over time because occupational goods are constant over time.

Given sectoral outputs, output of the final good in the uninfected economy is is given by (1). This is a stationary economy with the occupations choices, population distribution across occupations, sectoral output, the final good as well as all prices remain constant over time.

\subsection{A Special Case}

There is a special case of the model which will be useful to analyze below. Specifically, consider the case where the following condition holds: 


\section{Condition 1.}

$$
\rho=\rho^{j}=1 \text { for all } j
$$

Under Condition 1, equations (2) and (5) imply that $P_{t}(i)=P_{t}^{j}=1$. Hence, all prices are constant and equal to one. This directly implies that we must have $w_{t}^{k}(i)=w^{k}(i)=A_{i}^{k}$ and $w_{I}^{k}(i)=\gamma_{I}^{k} w^{k}(i)$. Thus, all occupational wages are also constant.

It is straightforward to verify that under Condition 1 we must have

$$
Y_{t}=\int_{i=0}^{1} L_{t}(i) d i
$$

\section{A Pandemic}

We shall now study the outbreak of a pandemic in the context of the special case of the model outlined in Section 2.3 above. Suppose that starting at some date $t=0$, a fraction $\epsilon_{0}$ of the population becomes infected with the virus. Hence, the measure $I_{0}=\epsilon_{0} L_{0}$ of individuals becomes infected. This information is public knowledge. Infection can be spread in multiple ways. Our focus is infection through the workplace, but we also allow for infection through random association (e.g. through leisure activities), and through consumption activities, such as retail. We assume that these second types of infection cannot be avoided, but individuals can reduce risk by choosing to work at home. ${ }^{3}$

In the following we shall denote the lifetime utility value of susceptible, infected and recovered individuals in occupation $i$ at date $t$ with $V^{S}(i, t), V^{I}(i, t), V^{R}(i, t)$, respectively. It will prove useful to first describe the choices of recovered agents, then those of infected agents and finally the choices of susceptible agents.

\subsection{Recovered individuals}

Recovered individuals are those who contracted the disease and survived. They are as productive in the labour market as susceptible individuals. The choices of a recovered agent $i$ at date $t$ working

\footnotetext{
${ }^{3}$ Endogenous choice of activities with respect to leisure and shopping activity are of course important, but our objective in this study is essentially on the implications of the pandemic for the labour market and employment differences across occupations.
} 
in location $j=h, m$ are determined by

$$
\begin{gathered}
V^{R h}(i, t)=\ln w^{h}(i)+\beta \operatorname{Max}\left\{V^{R h}(i, t+1), V^{R m}(i, t+1)\right\} \\
V^{R m}(i, t)=\ln w^{m}(i)+\beta \operatorname{Max}\left\{V^{R h}(i, t+1), V^{R m}(i, t+1)\right\}
\end{gathered}
$$

Since the continuation values from both home and market work (the second terms on the right hand side of the two equations above) are the same, the threshold occupation for recovered agents is given by

$$
w^{h}\left(\bar{i}^{R}\right)=w^{m}\left(\bar{i}^{R}\right)
$$

This defines the measure of occupations in which recovered agents work in the market as $\theta^{R}=1-\bar{i}^{R}$. Crucially, the constancy of occupational wages implies that this measure of recovered agents working in the market remains constant over time.

The preceding implies that (a) a recovered agent in occupation $i$ chooses to always work at home or always in the market; (b) $V^{R k}, k=h, m$ remains constant over time; and (c) the threshold $\bar{i}^{R}$ remains constant. We collect these results in the following:

$$
\begin{gathered}
V^{R h}(i, t)=V^{R h}(i)=\frac{\ln w^{h}(i)}{1-\beta} \\
V^{R m}(i, t)=V^{R m}(i)=\frac{\ln w^{m}(i)}{1-\beta} \\
(1-\beta) V^{R}(i)=\operatorname{Max}\left\{\ln w^{h}(i), \ln w^{m}(i)\right\}
\end{gathered}
$$

\section{$3.2 \quad$ Infected individuals}

To determine the lifetime utility of an infected agent $V^{I}(i)$, we assume that infected individuals can earn $w_{I}^{h}(i)$ in home work, and $w_{I}^{m}(i)$ in market work. As noted above, we assume that $w_{I}^{h}(i)<$ $w^{h}(i)$ and $w_{I}^{m}(i)<w^{m}(i)$ for all $i$. The assumptions capture the realistic scenario of an infected worker being less productive than a healthy worker. Infected individuals recover with probability $\pi_{R}$ and die with probability $\pi_{D}$. These probabilities are assumed to be time invariant in the current formulation. ${ }^{4}$

\footnotetext{
${ }^{4}$ In subsequent analysis we can allow for $\pi_{D}$ to vary based on the degree of congestion in the capacity of the health system.
} 
An infected individual's value functions from working either at home or in the market are defined as

$$
\begin{aligned}
V^{I h}(i, t) & =\ln w_{I}^{h}(i)+\beta\left[\left(1-\pi_{R}-\pi_{D}\right) \operatorname{Max}\left\{V^{I h}(i, t+1), V^{I m}(i, t+1)\right\}+\pi_{R} V^{R}(i, t+1)\right] \\
V^{I m}(i, t) & =\ln w_{I}^{m}(i)+\beta\left[\left(1-\pi_{R}-\pi_{D}\right) \operatorname{Max}\left\{V^{I h}(i, t+1), V^{I m}(i, t+1)\right\}+\pi_{R} V^{R}(i, t+1)\right]
\end{aligned}
$$

The cutoff market occupation for the set of infected individuals will be determined by $V^{I h}\left(\bar{i}^{I}, t\right)=$ $V^{I m}\left(\bar{i}^{I}, t\right)$. Since the continuation values from both market work and home work today are identical, the cutoff condition reduces to

$$
w_{I}^{h}\left(\bar{i}^{I}\right)=w_{I}^{m}\left(\bar{i}^{I}\right)
$$

The associated measure of occupations with infected people working in the marketplace is $\theta^{I}=$ $1-\bar{i}^{I}$. Note that the constancy of occupational wages implies that both $\bar{i}^{I}$ and $\theta^{I}$ are constant over time.

These results can be collected in the following expressions:

$$
\begin{gathered}
V^{I h}(i, t)=V^{I h}(i)=\frac{\ln w_{I}^{h}(i)+\beta \pi_{R} V^{R}(i)}{1-\beta\left(1-\pi_{R}-\pi_{D}\right)} \\
V^{I m}(i, t)=V^{I m}(i)=\frac{\ln w_{I}^{m}(i)+\beta \pi_{R} V^{R}(i)}{1-\beta\left(1-\pi_{R}-\pi_{D}\right)} \\
V^{I}(i)=\operatorname{Max}\left\{V^{I h}(i), V^{I m}(i)\right\}
\end{gathered}
$$

In deriving these expressions we have used the fact that the lifetime value of a recovered agent $V^{R}(i)$ is a constant over time. We established that above.

\subsection{Susceptible individuals}

Having described the choices of recovered and infected agents, we now turn to susceptible agents. For these individuals, their current choices have implications for their utility continuation values since susceptible agents are at risk of contracting the virus.

There are three ways in which an individual can get infected. The first is through interactions with infected people while working in the market, which we denote by $\pi_{t}^{m}$. The second is in the 
process of random interactions with infected people, through physical closeness in leisure activities or through travel, for instance. We denote this risk by $\pi_{t}^{I}$. Finally, we allow for infections through consumption activity, intended to capture the interaction of individuals through retail activity. We denote this risk as $\pi_{t}^{c}$. While $\pi_{t}^{I}$ and $\pi_{t}^{c}$ are common to all susceptible individuals, the risk of infection at work is specific to agents who choose to work in the market rather than at home. $\pi_{t}^{c}$, $\pi_{t}^{I}$ and $\pi_{t}^{m}$ fluctuate over time as the market participation of agents changes in the economy and as the overall number of infected people changes.

When there is a risk of infection from market work, the value functions for a susceptible individual in occupation $i$ are

$$
\begin{gathered}
V^{S h}(i, t)=\ln w^{h}(i)+\beta\left[\left(\pi_{t}^{I}+\pi_{t}^{c}\right) V^{I}(i)+\left(1-\pi_{t}^{c}-\pi_{t}^{I}\right) \operatorname{Max}\left\{V^{S h}(i, t+1), V^{S m}(i, t+1)\right\}\right] \\
V^{S m}(i, t)=\ln w^{m}(i)+\beta\left[\left(\pi_{t}^{m}+\pi_{t}^{I}+\pi_{t}^{c}\right) V^{I}(i)+\left(1-\pi_{t}^{m}-\pi_{t}^{I}-\pi_{t}^{c}\right) \operatorname{Max}\left\{V^{S h}(i, t+1), V^{S m}(i, t+1)\right\}\right]
\end{gathered}
$$

where $V^{I}(i)$ is the function that we solved for above.

From the point of view of a susceptible person, the probability of being infected in the market place is equal to $\pi_{m}=\frac{\epsilon S_{t}^{m} I_{t}^{m}}{S_{t}^{m}}=\epsilon I_{t}^{m}$. Individuals take this probability of getting infected to be given exogenously when they make their decisions regarding market versus home work in their occupations.

The cutoff $\bar{i}^{S}$ is determined by

$$
\ln w^{h}\left(\bar{i}^{S}\right)=\ln w^{m}\left(\bar{i}^{S}\right)+\beta \pi_{t}^{m}\left[V^{I}\left(\bar{i}^{S}\right)-\operatorname{Max}\left\{V^{S h}\left(\bar{i}^{S}, t+1\right), V^{S m}\left(\bar{i}^{S}, t+1\right)\right\}\right]
$$

We now prove the following result that will be crucial in characterizing the solution:

Condition 2. $V^{I}(i)<\operatorname{Max}\left\{V^{S h}(i, t), V^{S m}(i, t)\right\}$ for all $i$ and all $t .^{5}$

Proposition 1. Condition 2 is necessary and sufficient for the threshold occupation $\bar{i}_{t}^{S}$ to be increasing in the probability of infection $\pi_{t}^{m}$.

\footnotetext{
${ }^{5}$ There always exists a weakly positive wage from home or market work which will guarantee that this condition holds.
} 
Proof. From the expressions for $V^{S h}(i)$ and $V^{S m}(i)$ above we get

$$
V^{S h}(i, t)-V^{S m}(i, t)=\ln w^{h}(i)-\ln w^{m}(i)-\beta \pi_{t}^{m}\left[V^{I}(i)-\operatorname{Max}\left\{V^{S h}(i, t+1), V^{S m}(i, t+1)\right\}\right]
$$

Differentiating this with respect to $\pi_{t}^{m}$ gives

$$
\frac{\partial\left[V^{S h}(i, t)-V^{S m}(i, t)\right]}{\partial \pi_{t}^{m}}=\left[\operatorname{Max}\left\{V^{S h}(i, t+1), V^{S m}(i, t+1)\right\}-V^{I}(i)\right]
$$

This derivative is positive under Condition 2. The threshold condition is $V^{S h}\left(\bar{i}^{S}\right)=V^{S m}\left(\bar{i}^{S}\right)$. Since $\frac{\partial\left[V^{S h}(i)-V^{S m}(i)\right]}{\partial \pi_{t}^{m}}>0$, it follows that $V^{S h}\left(\bar{i}^{S}, t+1\right)>V^{S m}\left(\bar{i}^{S}, t+1\right)$ if and only if $\pi_{t+1}^{m}>\pi_{t}^{m}$. Hence, the threshold $\bar{i}_{t+1}^{S}>\bar{i}_{t}^{S}$ when $\pi_{t+1}^{m}>\pi_{t}^{m} \operatorname{since} \ln w^{m}(i)-\ln w^{h}(i)$ is increasing in $i$. Q.E.D.

Corollary 1. Along paths with a falling probability of infection from market work $\pi_{t}^{m}$, the threshold occupation $\bar{i}^{S}$ declines so that more occupations become market based over time, or $\theta^{S}=1-\bar{i}^{S}$ rises.

The Proposition says that as long as getting infected reduces lifetime utility sufficiently, a higher risk of infection raises the benefit of working from home. Consequently, along paths with monotonically rising $\pi_{t}^{m}$, the threshold $\theta^{S}$ falls as $\bar{i}^{S}$ rises.

More generally however, during the evolving dynamics of the pandemic, $\pi_{t}^{m}$ will typically be nonmonotonic, rising initially as more infected individuals come in contact with susceptible individuals, but then falling as both the population of infected and susceptible individuals falls. In this case, $\bar{i}^{S}$ will move in a non-monotonic direction also. The path of $\bar{i}^{S}$ is then determined by the peak value of $\pi^{m}$ that is attained as the pandemic spreads. In this case we can establish Proposition 2

Proposition 2. Take a sequence of infection probabilities $\pi_{1}^{m} \ldots \pi_{T}^{m}$ such that $\pi_{1}^{m}<\pi_{2}^{m}<\ldots<$ $\pi_{M}^{m}$, and $\pi_{M}^{m}>\pi_{M+1}^{m}>\ldots>\pi_{T}^{m}$.

Then for $\pi_{t}^{m}<\pi_{M}^{m}, \bar{i}^{S}$ is governed by the dynamics:

$$
\begin{gathered}
\ln w^{h}\left(\bar{i}^{S}\right)=\ln w^{m}(\bar{i})+\beta \pi_{t}^{m}\left[V^{I}\left(\bar{i}^{S}, t+1\right)-V^{s h}\left(\bar{i}^{S}, t+1\right)\right] \\
V^{S h}(i, t)=\ln w^{h}(i)+\beta\left[\left(\pi_{t}^{I}+\pi_{t}^{c}\right) V^{I}(i)+\left(1-\pi_{t}^{c}-\pi_{t}^{I}\right) V^{S h}(i, t+1)\right]
\end{gathered}
$$


and for $\pi_{t}^{m}>\pi_{M}^{m}, \bar{i}^{S}$ is governed by the dynamics:

$$
\begin{gathered}
\ln w^{h}\left(\bar{i}^{S}\right)=\ln w^{m}(\bar{i})+\beta \pi_{t}^{m}\left[V^{I}\left(\bar{i}^{S}, t+1\right)-V^{S m}\left(\bar{i}^{S}, t+1\right)\right] \\
V^{S m}(i, t)=\ln w^{m}(i)+\beta\left[\left(\pi_{t}^{m}+\pi_{t}^{I}+\pi_{t}^{c}\right) V^{I}(i)+\left(1-\pi_{t}^{m}-\pi_{t}^{I}-\pi_{t}^{c}\right) V^{S m}(i, t+1)\right]
\end{gathered}
$$

Proof. This follows directly from the proof of proposition 1 when combined with the non-monotonic path of $\pi_{t}^{m}$

Proposition 3. Under Condition 2, the threshold occupation of susceptible individuals, $\bar{i}_{t}^{S}$, is greater than the threshold for recovered agents $\bar{i}^{R}$ for all $t$. Hence, the share of occupations under market work is greater for recovered individuals than susceptible agents, or $\theta^{R}>\theta_{t}^{S}$.

Proof. The cutoff condition for recovered agents can be written as $\ln w^{m}\left(\bar{i}^{R}\right)-\ln w^{h}\left(\bar{i}^{R}\right)=0$. The threshold condition for susceptible agents is

$$
\ln w^{m}\left(\bar{i}^{S}\right)-\ln w^{h}\left(\bar{i}^{S}\right)=\beta \pi_{t}^{m}\left[\operatorname{Max}\left\{V^{S h}\left(\bar{i}^{S}, t+1\right), V^{s m}\left(\bar{i}^{S}, t+1\right)\right\}-V^{I}(\bar{i})\right]>0
$$

where the last inequality holds under Condition 2. Since $\ln w^{m}(i)-\ln w^{h}(i)$ is rising in $i$, we must have $\bar{i}_{t}^{S}>\bar{i}^{R}$. The statement on the share of market occupations for types $R$ and $I$ follows trivially as $\theta^{j}=1-\bar{i}^{j}$ for $j=R, I$.

Q.E.D.

\subsection{Occupation populations}

The absolute measures of individuals working in the market in this economy at any date $t$ is the sum of susceptible, infected and recovered individuals working in market occupations: $P_{t}^{m}=$ $S_{t}^{m}+I_{t}^{m}+R_{t}^{m}$. The number of market workers within each group is given by

$$
\begin{aligned}
S_{t}^{m} & =\int_{\bar{i}_{t}^{S}}^{1} S_{t}(i) d i \\
I_{t}^{m} & =\int_{\bar{i}^{I}}^{1} I_{t}(i) d i \\
R_{t}^{m} & =\int_{\bar{i}^{R}}^{1} R_{t}(i) d i
\end{aligned}
$$

Equation 11 is the measure of susceptible individuals engaged in market work. 
Since infections are dependent on whether susceptible individuals work in the market or at home, we also need to describe the evolution of occupation specific populations in each of the three groups $S, I$ and $R$. The evolution of susceptible agents in occupation $i$ is given by

$$
S_{t+1}(i)= \begin{cases}S_{t}(i)-\epsilon S_{t}(i) I_{t}^{m}-\pi_{c} C_{t}^{S}(i) C_{t}^{I}-\pi S_{t}(i) I_{t} & \text { if } i>\bar{i}_{t}^{S} \\ S_{t}(i)-\pi_{c} C_{t}^{S}(i) C_{t}^{I}-\pi S_{t}(i) I_{t} & \text { if } i \leq \bar{i}_{t}^{S}\end{cases}
$$

where $\epsilon$ is the matching rate which generates new infections through work and $\pi$ is the probability of infection from random contact between susceptible and infected people. $\pi_{c}$ is the exogenous probability of getting infected due to random interaction between consumption of the susceptible and infected individuals. $C_{t}^{S}$ denotes aggregate consumption of susceptible individuals while $C_{t}^{I}$ is total consumption of infected individuals. We shall solve for these below. In deriving the above, we have used the fact that only susceptible agents in occupations that are provided in the market, $i>\bar{i}_{t}^{S}$, risk getting infected.

Integrating Equation 14 over all occupations gives the evolution of the number of susceptible individuals as

$$
S_{t+1}=S_{t}-\epsilon S_{t}^{m} I_{t}^{m}-\pi_{c} C_{t}^{S} C_{t}^{I}-\pi S_{t} I_{t}
$$

Similarly, the number of infected people in occupation $i$ evolves according to

$$
I_{t+1}(i)= \begin{cases}\left(1-\pi_{R}-\pi_{D}\right) I_{t}(i)+\epsilon S_{t}(i) I_{t}^{m}+\pi_{c} C_{t}^{S}(i) C_{t}^{I}+\pi S_{t}(i) I_{t} & \text { if } i>\bar{i}_{t}^{S} \\ \left(1-\pi_{R}-\pi_{D}\right) I_{t}(i)+\pi_{c} C_{t}^{S}(i) C_{t}^{I}+\pi S_{t}(i) I_{t} & \text { if } i \leq \bar{i}_{t}^{S}\end{cases}
$$

Integrating Equation 16 over all occupations gives the evolution of infected individuals in the economy as

$$
I_{t+1}=\left(1-\pi_{R}-\pi_{D}\right) I_{t}+\epsilon S_{t}^{m} I_{t}^{m}+\pi_{c} C_{t}^{S} C_{t}^{I}+\pi S_{t} I_{t}
$$

Lastly, the measure of recovered individuals in occupation $i$ is given by

$$
R_{t+1}(i)=R_{t}(i)+\pi_{R} I_{t}(i)
$$


Integrating this over all occupations yields the evolution of recovered agents as

$$
R_{t+1}=R_{t}+\pi_{R} I_{t}
$$

Noting that the total population is $L_{t}=S_{t}+I_{t}+R_{t}$, we can sum equations 15, 17 and 19 to get the evolution of the total populations as

$$
L_{t+1}=L_{t}-\pi_{d} I_{t}
$$

We assume that the initially infected population is distributed proportionally across all occupations so that

$$
\begin{aligned}
& S_{0}(i)=\left(1-\varepsilon_{0}\right) L_{0}(i) \\
& I_{0}(i)=\varepsilon_{0} L_{0}(i) \\
& R_{0}(i)=0
\end{aligned}
$$

\subsection{Consumption}

Aggregating over consumption by all individuals in each occupation gives the occupation specific aggregate consumption as

$$
\begin{aligned}
& C_{t}^{S}(i)=c_{t}^{S}(i) S_{t}(i) \\
& C_{t}^{I}(i)=c_{t}^{I}(i) I_{t}(i) \\
& C_{t}^{R}(i)=c_{t}^{R}(i) R_{t}(i)
\end{aligned}
$$

Hence, total consumption in the economy, which must be the sum of consumption by each group, is

$$
C_{t}=\int_{i}\left\{C_{t}^{S}(i)+C_{t}^{I}(i)+C_{t}^{R}(i)\right\} d i=C_{t}^{S}+C_{t}^{I}+C_{t}^{R}
$$




\subsection{Government}

The government maintains a balanced budget by rebating all its tax revenues through lump sum transfers to individuals. This implies that

$$
G_{t}=g_{t} L_{t}=\tau^{m} \int_{i=0}^{1} A_{i}^{m}\left\{S_{t}^{m}(i)+\gamma_{I}^{m} I_{t}^{m}(i)+R_{t}^{m}(i)\right\} d i
$$

\subsection{Market clearing}

We conclude the description of the key relationships by describing the market clearing condition for the final good. Since, the government rebates all tax revenues to individuals in the form of lump sum transfers we have

$$
C_{t}=Y_{t}
$$

\section{Quantitative Results}

We now turn to quantifying the special case of the model under Condition 1 where all the elasticities of substitution between occupations in producing the sectoral output and between sectors in the final goods technology are equal to unity, as are the sectoral weights. Recall that in this special case, GDP becomes just a sum of all the occupational outputs. The model has a number of margins that affect outcomes. We flesh out some of these through comparative static exercises on the parameters that control these margins.

\subsection{Calibration}

There are ten key parameters in the model. The parameters are mostly taken from Eichenbaum et al. (2020). They calibrate the probability parameters $\epsilon, \pi_{C}$, and $\pi$ to jointly match the probabilities of infection from consumption, market work and random interactions in the USA. They estimate these probabilities by combining the estimates of Ferguson et al. (2006) with the Bureau of Labour Statistics 2018 Time Use Survey and the 2018 BLS data on total workers. Their estimates imply that 16 percent of transmissions occur during consumption, 17 percent at work and remainder are through random interactions.

We follow Atkeson (2020) in assuming that it takes 18 days to either recover from the virus 
Table 1: Parameter Values for Calibration

\begin{tabular}{lll}
\hline \hline Target Variable & Parameter & Value \\
\hline Probability of random infection & $\pi$ & 0.40 \\
Probability of infection while consuming & $\pi_{C}$ & $1.5924 \mathrm{e}-07$ \\
Probability of infection through market work & $\varepsilon$ & 0.11 \\
Probability of death & $\pi_{D}$ & 0.002 \\
Probability of recovery & $\pi_{R}$ & 0.387 \\
Share of work-from-home & $\bar{\imath}$ & 0.06 \\
Weekly discount factor & $\beta$ & 0.999 \\
Relative home productivity of infected & $\gamma_{I}^{h}$ & 0.8 \\
Relative market productivity of infected & $\gamma_{I}^{m}$ & 0.8 \\
Initial fraction infected & $\epsilon_{0}$ & 0.001 \\
\hline \hline
\end{tabular}

or die from it. Since our time unit is a week, we set $\pi_{D}+\pi_{R}=7 / 18$. Based on South Korean data, Eichenbaum et al. (2020) estimate the mortality rate from the virus to be 0.5 percent. This yields individual estimates for $\pi_{R}$ and $\pi_{D}$. The baseline values for the relative productivity of infected people is set to 0.8. They set this value based on the China Center for Disease Control and Prevention's estimate that 80 percent of infected people are asymptomatic and that symptomatic individuals withdraw from work. The values of the discount factor and the initially infected are also taken from Eichenbaum et al. (2020).

We estimate the share of individuals engaged in occupations classified as fully working from home at 6 percent. This is based on estimates from the 2016 Canadian Census. The weekly discount factor is computed by using the annual discount factor of 0.96 and converting it to its weekly equivalent. Lastly, we start the pandemic off by assuming that there an exogenous infection of 0.1 percent of the population at an initial date $t=0$. The values for these parameters that we use for the simulations are given in Table 1.

\subsection{Data}

We implement the model using occupations mapped into the share of occupations in British Columbia using the National Occupational Classifications (NOC) from Statistics Canada Labour Force Survey and partly from the Canadian Census of 2016. Figure 1 shows the different occupations at the 2 digit NOC level with their share based on the November 2019 Labour Force Survey (left hand side axis) as well as the measure of each occupation that reported some degree of working from home from the Canadian 2016 census (right hand side axis). 
Figure 1: NOC occupations and 'Work From Home'

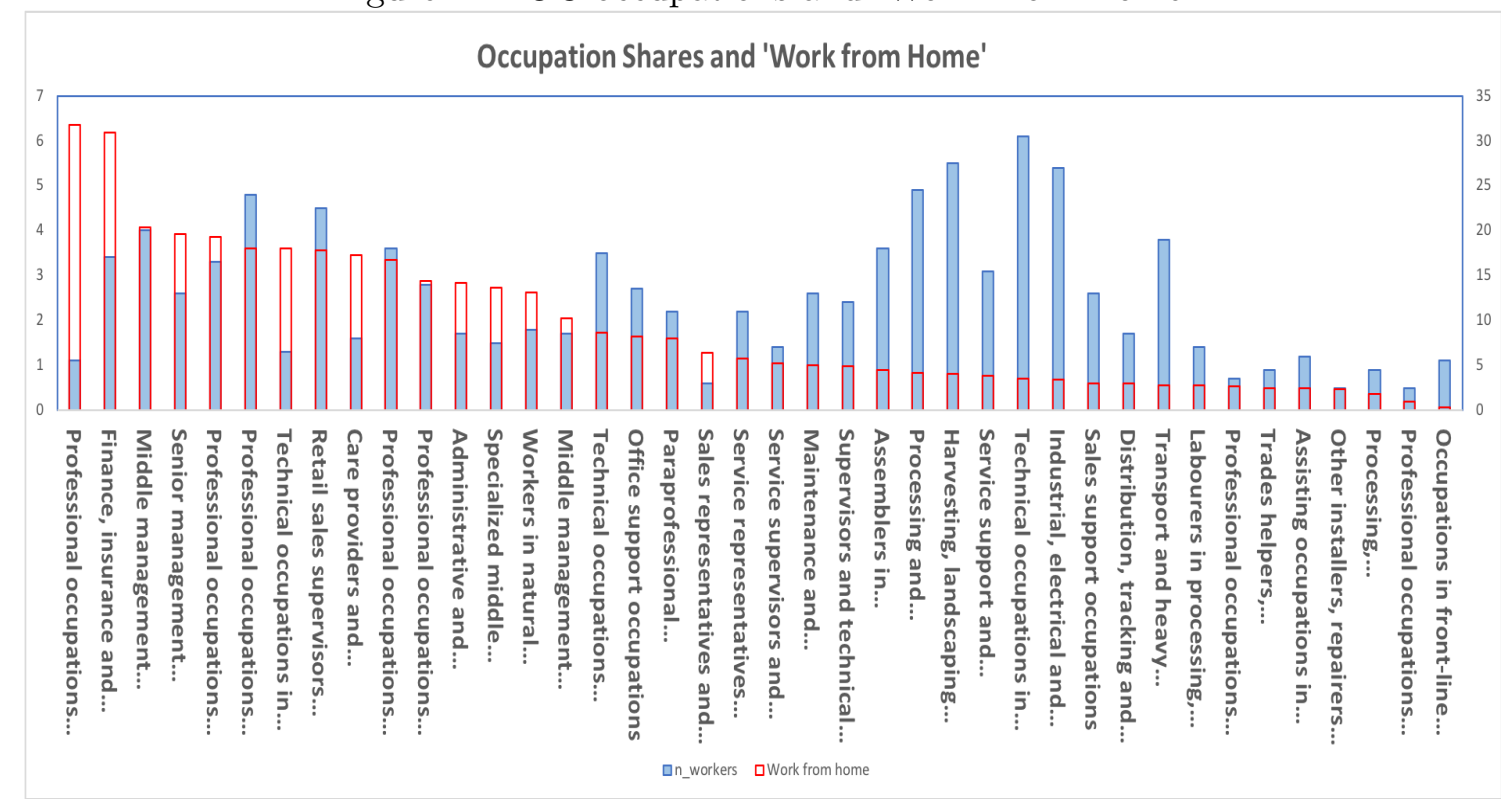

Figure 2 reports the change in employment by occupation from February to April, 2020, and then from April 2020 to June 2020 (based on May Labour Force Survey from Statistics Canada). Each change is weighted by the share of the occupation in the total labour force. The first two months of the pandemic saw job losses on almost 400 thousand in BC. Hardest hit were occupations in service sectors such as customer service sales representatives, and service support occupations. Other occupations, such as senior managers, were almost untouched. In addition, occupations related to essential services, such as nursing occupations, or occupations in front line protection services increased in employment during the first period. The June Labour Force Survey then shows a pick-up of approximately 200 thousand jobs from the April low point. The message from Figure 2 indicates substantial heterogeneity in job losses among occupations.

The model set out above does not have an explicit role for unemployment. We assume each occupation either works at home or in the market. However, we can connect the model to the data by interpreting large job losses among occupations which face a major loss of income from home working as being equivalent to unemployment, while other occupations such as senior management or professional occupations in business and finance can easily remain in the category of being employed while either continuing to work from home or switching to work from home following the outbreak of the pandemic. 
Figure 2: Change in Occupational Employment, February to June, 2020

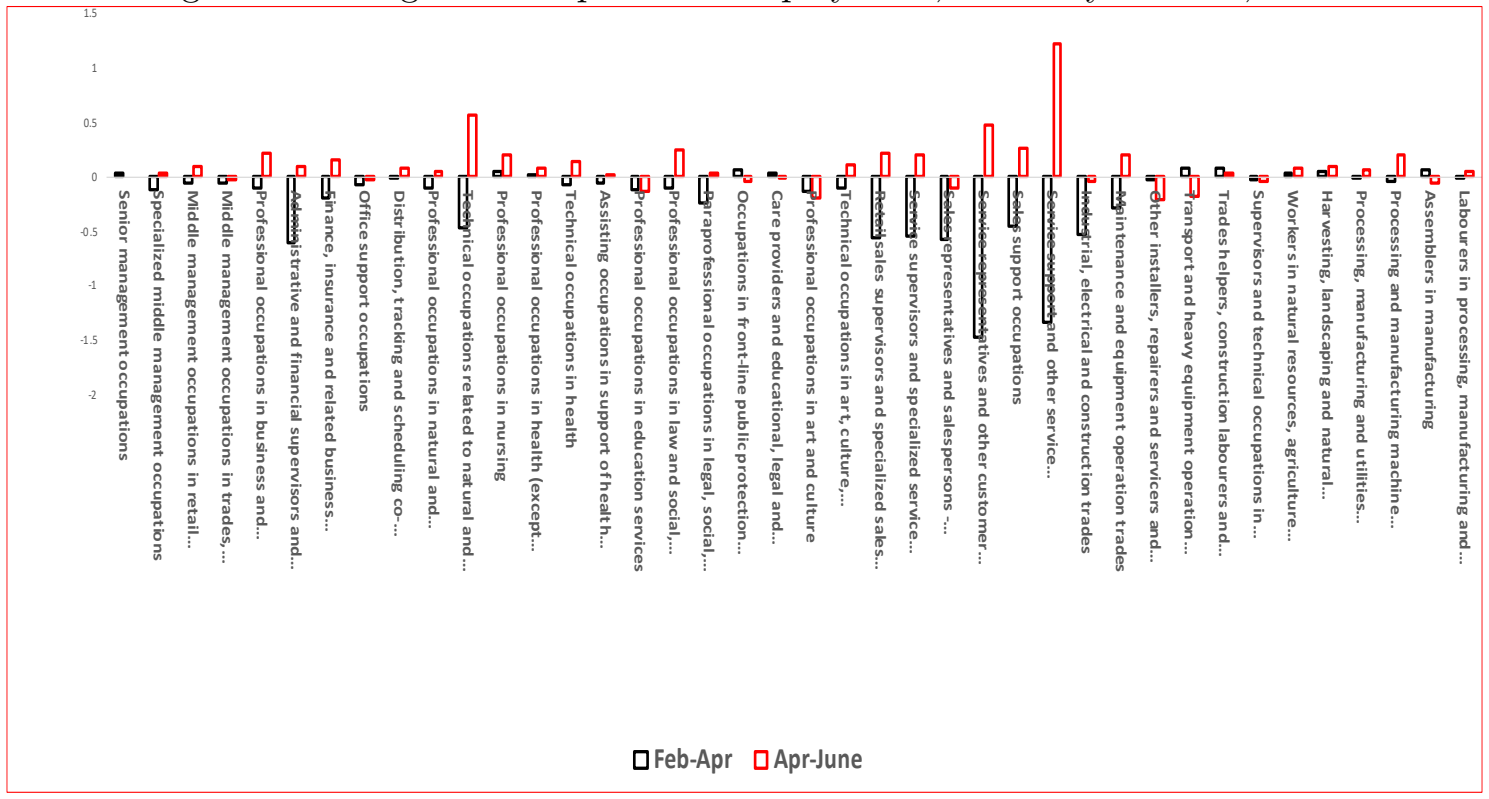

\subsection{Estimating the home wage schedule}

There are two complications in mapping the available data on occupation distribution and wages to the model. The first is that in the steady state of the model, occupations are characterized by either all individuals working from home or in the market. The data however reveals a mix of market and home work shares in each occupation. A second issue is the measurement of wages. In the model individuals make labour supply decisions on the basis of occupation specific wages for home versus market work. While we do have occupation specific wages from Census 2016, these are equilibrium wages and in most cases refer to wages paid for working in the market. We do not observe home wages separately.

We get around the first problem by adopting a threshold approach to classifying occupations into working from home or in the market. Specifically, we classify all occupations with workfrom-home shares above the threshold to be entirely working from home while those below are classified as working in the market. In a 2017 survey by Regus (2017) approximately 10 percent of workers reported that they work exclusively from home. The 2016 Canadian census reports, for each occupation, the share of workers who work from home. In order to match the overall 10 percent share of home work, we choose the threshold share of working from home as $\hat{\lambda}=0.194$ 
${ }^{6}$. This represents the 90 th percentile in the occupational distribution of work-from-home shares. This chosen threshold leaves four occupations (professional occupations in art, insurance, middle management, and senior management) that are classified as entirely working from home in the initial steady state.

In order to map the model to the data we also need a measure of wages from working at home in each occupation. Since our data on occupational wages only reveals equilibrium wages, the home wage schedule for workers who work exclusively in the market during normal times needs to be imputed. In order to make progress, we start with the assumption that the difference between the home and market wage schedule in any occupation is a linear, increasing function of the ease of performing the occupation specific tasks from home. We proxy the ease with which tasks can be performed from home in an occupation by the fraction of workers in that occupation who work from home.

Using $\lambda(i)$ to denote the share of workers in an occupation that works from home, the home wage schedule is computed as

$$
w^{h}(i)=w^{m}(i)[1+(\lambda(i)-\hat{\lambda})]
$$

where $w^{m}(i)$ is the median weekly wage in occupation $i$. Hence, occupations with home work shares below the threshold will have home wages below the market wage while those with home work shares above the threshold will have home wages that exceed the market wage. As noted above, our data contains information on 40 2-digit occupations. Data on occupation wages comes from the Census 2016.

Figure 3 shows the estimated relative home wage schedule along with the work-from-home shares in all the occupations in our data.

In the following we shall use this estimated home wage premium schedule to determine optimal choices by individuals within each occupation.

\footnotetext{
${ }^{6}$ The employment share of individuals working at home over all occupations is estimated at 10 percent. But the model definition of working at home instead requires that we compute the employment share of those occupations which are performed at home. This estimate from the data is 6 percent.
} 
Figure 3: Estimated Relative Home Wage Schedule

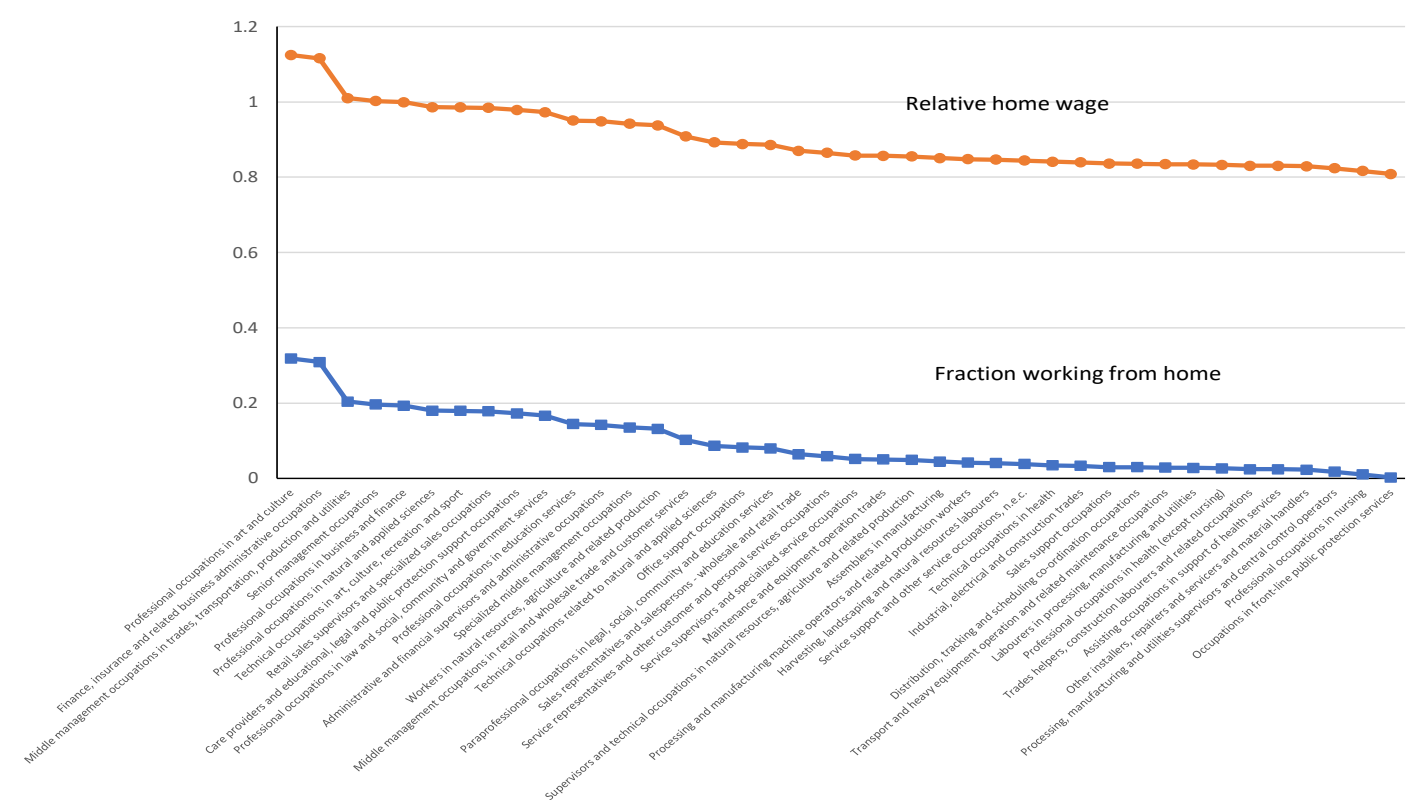

\subsection{Results}

We now show the dynamics of the model starting from a steady state when 0.1 percent of the population gets exogenously infected with a contagious virus. We start by showing the dynamics in the baseline case of the model with parameter values as in Table 1. Figure 4 depicts the dynamic behaviour of the key variables. The time unit for our analysis is weeks.

The solid blue line shows the dynamics in the baseline case of the model. The infection rate peaks at slightly under 5 percent after around 7 months from the initial infection. The pandemic kills a cumulated 0.25 percent of the population. These numbers imply that for a country with 30 million people, 1.5 million people get infected while 75,000 people die. Currently in Canada, total reported cases are 128,000. But it is widely understood that infection rates are much higher than actually counted in tests. The CDC in the US estimates that infection rates are up to 10 times those officially reported Mandavilli (2020). With this adjustment, the infection rates implied by the model are of the same magnitude as suggested by the data.

The economic costs of the pandemic occur due to both a decline in market employment as well as a fall in productivity due to infection. At the deepest point of the recession, which occurs at the same time as the peak of the infections, market employment falls by around 45 percentage points 
Figure 4: Endogenous versus Exogenous Choice of Market and Home Work

—Endogeneous

- - Exogenous
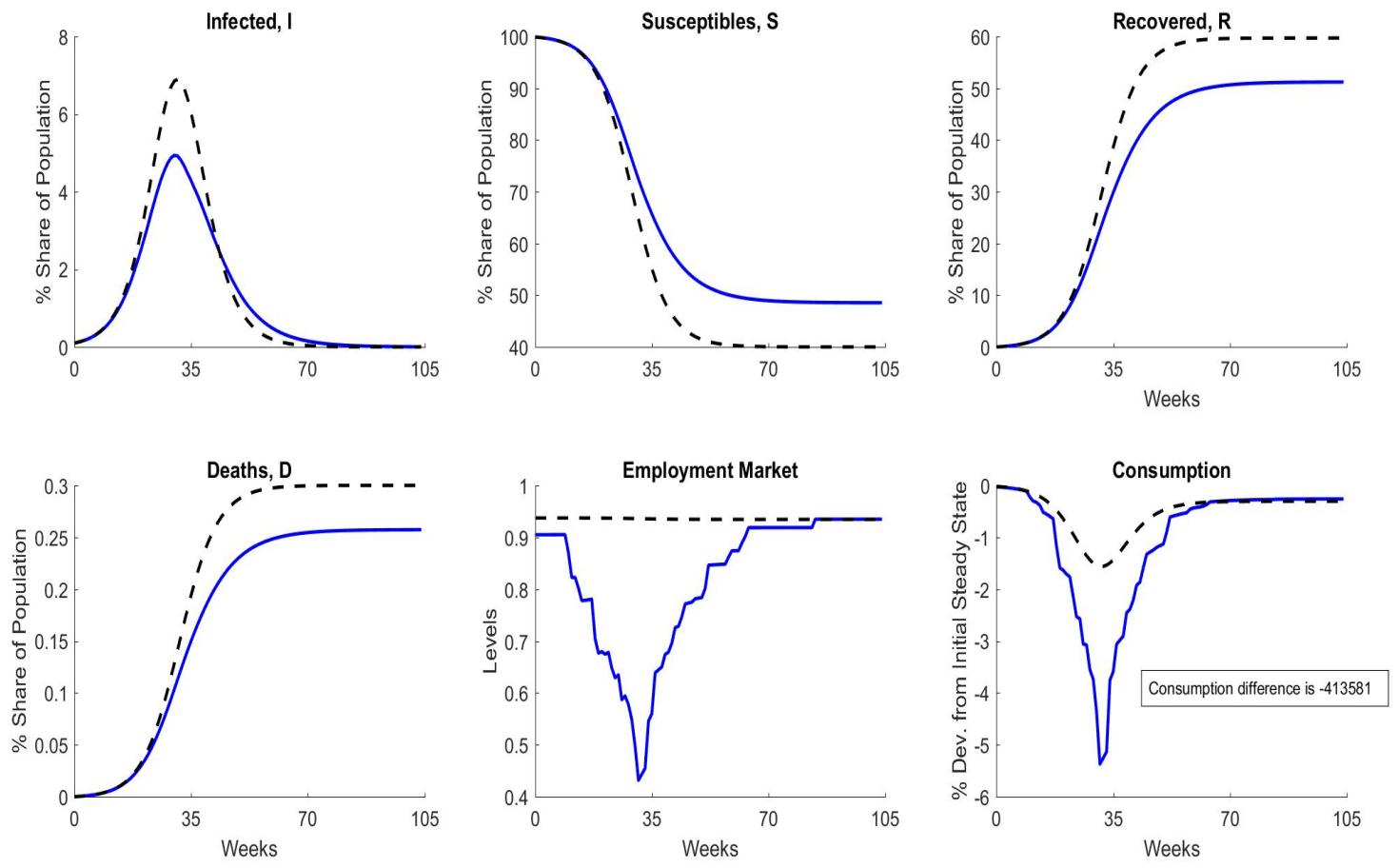

while output and consumption decline by over 5 percent relative to steady state. These numbers appear to be in line with the initial estimates of job losses and output contractions reported from Canada and around the world.

A distinguishing feature of the model is that private agents endogenously select into market versus working from home. Figure 4 shows the crucial role played by these endogenous work choices made by individuals. The dashed black line shows the dynamic macro-pandemic responses when the work location choices of individuals are shut down completely. The dashed lines in the figure show that when work choices are constrained to remain at the pre-pandemic level, the peak infection rate and the cumulated death rate is 2 percentage points and 0.05 percentage points higher, respectively, than in the endogenous choice case. The higher infection and death rates occur due to people continuing to work in the market instead of withdrawing to working from home. Relative to the endogenous choice case, consumption declines by almost 4 percentage points less in the exogenous choice case. Clearly, the effect of endogenous choice of work location is quantitatively substantial. 


\subsection{Temporary Lockdowns}

Countries globally have chosen various degrees of lockdowns to fight the spread of the infection. This aspect of policy behavior can be captured in the model through taxes on market production. How effective is shutting down markets in reducing the prevalence of infections? How costly is it? Figure 5 shows the effect of two different lockdown intensities. The first is a lockdown for 36 weeks with a $\tau=0.05$. The second is a shorter lockdown of 12 weeks but more intense with $\tau=0.12$. The figure also shows the baseline case of $\tau^{m}=0$ with the solid line. The dashed black line depicts the case with $\tau^{m}=0.05$ and the dashed red lines corresponds to $\tau^{m}=0.12$.

Figure 5: Varying the Intensity of a Lockdown
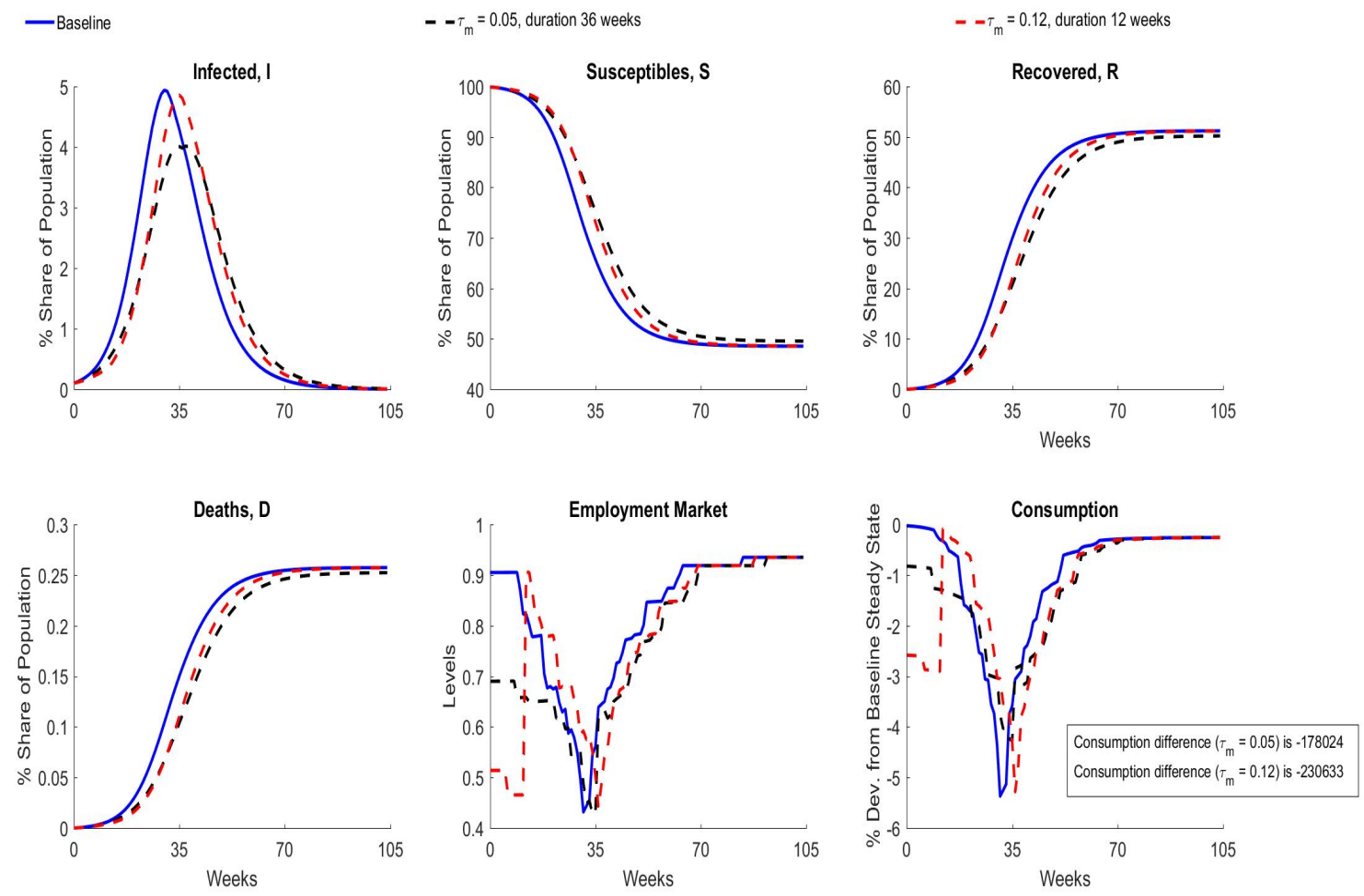

Figure 5 makes clear that a more intense but shorter lockdown of market work for 12 weeks does not materially alter either the peak infection rate or the cumulated number of deaths. It essentially delays the peak by the duration of the lockdown. Market employment collapses by over 40 percentage points on impact of the shock with attendant output losses of almost 3 percent relative to steady state. However, these effects are relatively short lived as the end of the lockdown results in a rapid recovery of market employment. Interestingly, the economy begins a fresh con- 
traction in market employment and output after the end of the lockdown, but this is entirely due to the endogenous response of individuals sheltering from infections and from the continuing rise of infections in the economy.

The other case is where the lockdown is less intense with $\tau=0.05$ but lasts for 36 weeks. Figure 5 shows that this longer lockdown does have the effect of significantly lowering the peak infection rate by 1 percentage point relative to the baseline. This policy is also less costly in terms of output. The reasons are twofold. First, the initial collapse in market work is lower under the less intense lockdown. Second, the lockdown lasts long enough to ensure that the pandemic reaches its peak before the program ends. Consequently, there is no renewed endogenous decline in market work and output after the end of the program.

An interesting feature of the temporary lockdown policies is that they have little impact on the long run outcome of the pandemic, in terms of total infections and deaths. This contrasts sharply with the impact of endogenous shifts out of market work. Comparing Figure 5 with Figure 4, we see that the final death rate from the pandemic is reduced from 0.3 to 0.25 percent of the population through endogenous response of individuals in their occupation location choices, which in itself represents a temporary phenomenon. The additional reduction in deaths coming from lockdowns is negligible.

While each of these policies have some impact on the infection curve, neither manages to completely 'flatten the curve' as described in media discussion of pandemic responses. Figure 6 shows a drastic lockdown policies, involving $\tau=0.20$ imposed for 52 weeks. This causes an immediate and complete shift to working from home for all occupations, and significantly reduces infections and final death rates, but this comes at a huge cost in terms of overall consumption.

\section{Robustness of Results}

Amongst the various assumptions underlying the baseline model, three appear to be potentially crucial. First, the model assumes that the infection risk from working in the market is common across all occupations. Second, we assumed that utility is log-linear in consumption. This leaves open the question of the sensitivity of the model to the degree of risk aversion. Third, the size of the output losses as well as the attitude to exposing oneself to the risk from market work has to 
Figure 6: An Extreme Lockdown Policy
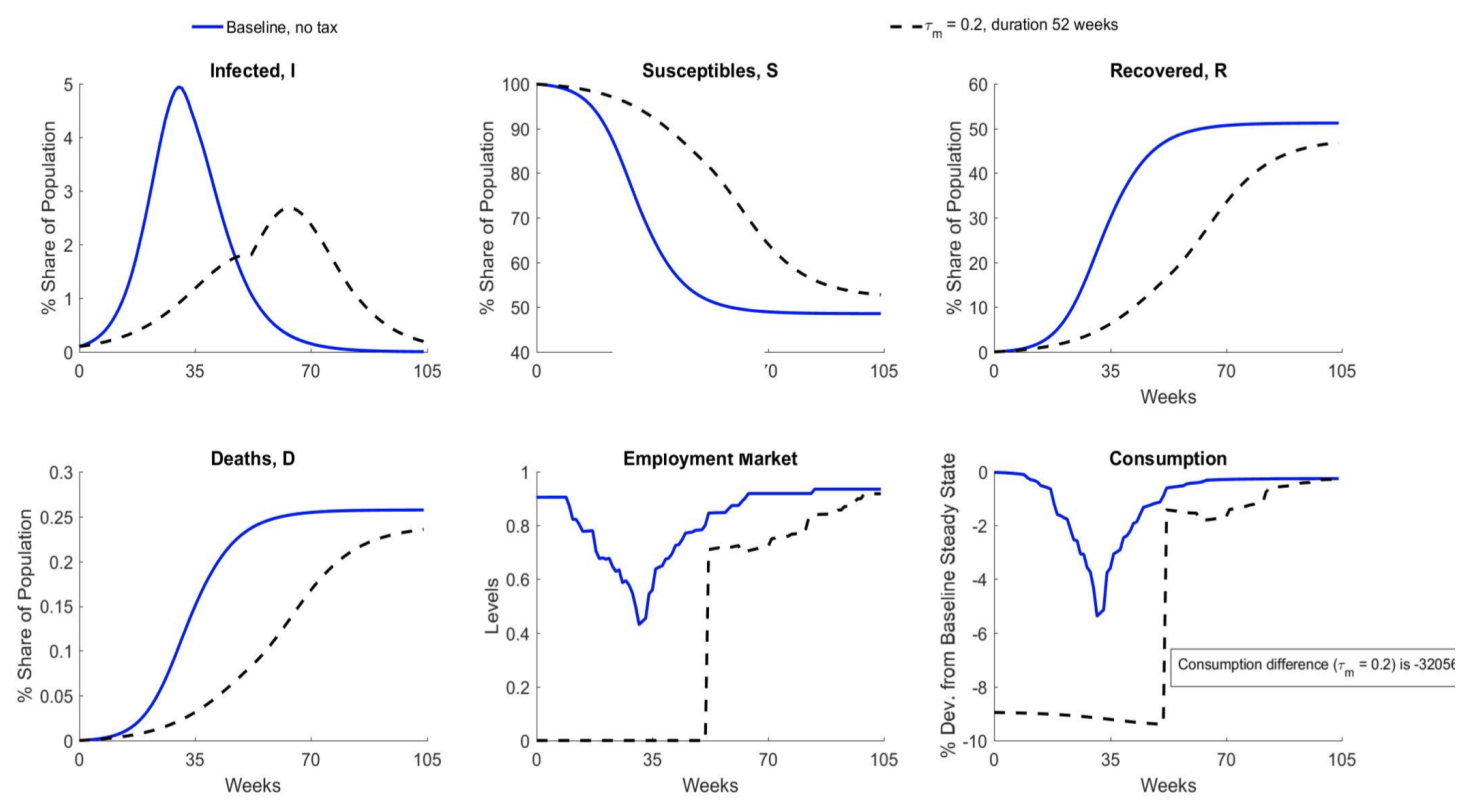

be dependent on the productivity of labour contingent on becoming infected. We now examine the importance of these three margins.

\section{$5.1 \quad$ Occupation-Specific Risk}

Thus far we assumed that $\pi^{m}$ was independent of occupation $i$. This is a strong assumption. The exposure to infection risk varies across occupations due to occupation specific characteristics like proximity to others at work, the degree of IT intensity of the occupation, the number of people one has to interact with at work, etc.. Using the VSE Risk-Tool, 2020, one can construct a 2digit NOC occupation level risk index. Figure 7 depicts the variation in this risk index across occupations. The figure clearly indicate that different occupations experience different degrees of infection risk, quite separately from their market versus home wage premium. Does this matter?

We examine the importance of occupation-specific risk by modifying the model. Recall that the probability of getting infected through market work was $\pi_{t}^{m}=\epsilon I_{t}^{m}$. We now modify this to

$$
\pi_{i t}^{m}=\epsilon_{i} I_{t}^{m}
$$


Figure 7: Indices by Occupation

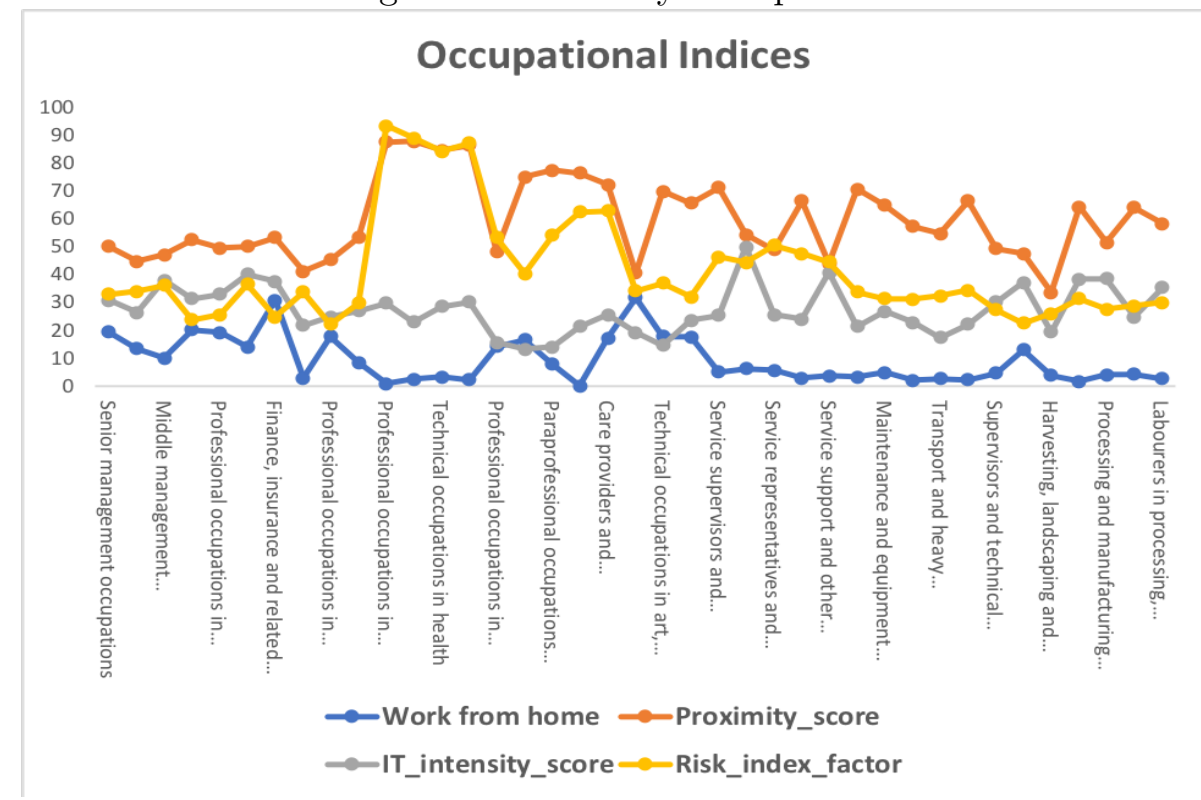

In order to compute the occupation-specific infection risk we first compute the mean risk factor across all occupations based on the VSE risk tool. We then define the risk factor proportionality of each occupation as

$$
z_{i}=\frac{\text { VSE risk index for occupation } i-\text { Mean risk index }}{\text { Mean risk index }}
$$

Using this, we compute the occupation-specific infection risk parameter $\epsilon_{i}$ as

$$
\epsilon_{i}=\epsilon\left(1+z_{i}\right)
$$

where $\epsilon$ is the common risk parameter that we were using before. Figure 8 compares the responses of the model under occupation specific risk with those under common risk. The dashed lines are the responses under common risk while the solid lines are the responses under occupation-specific risk. The key point to note is that the differences are relatively minor. Put differently, the results that we obtained under common infection risk across occupations are robust to accounting for occupation specific risk. 
Figure 8: Occupation-specific Infection Risk
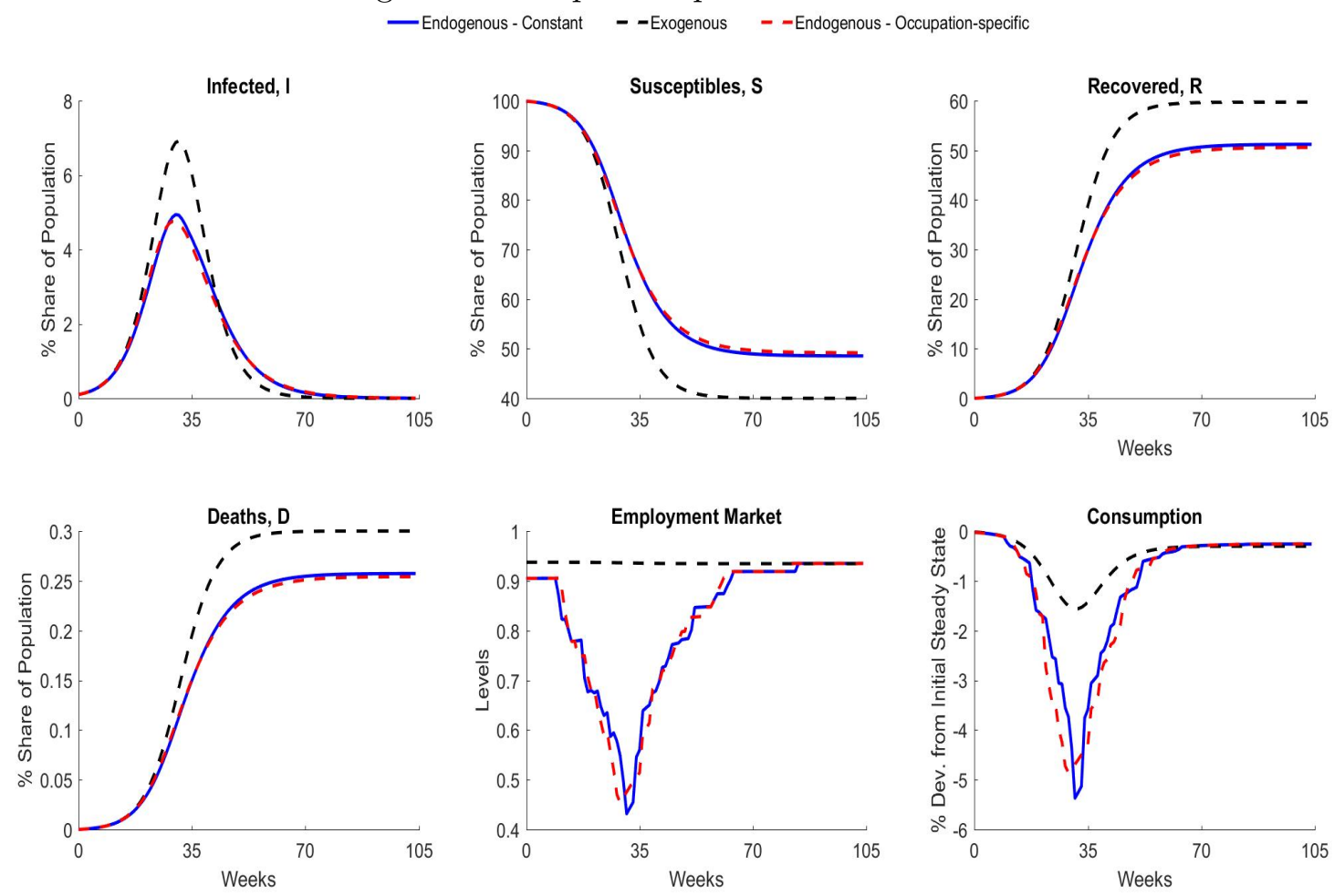

\subsection{Role of risk aversion}

We now examine the importance of the degree of risk aversion of individuals in driving the dynamics of the pandemic.

To study the importance of risk aversion, we assume that the periodic utility function of individuals is linear:

$$
u\left(c_{t}\right)=c_{t}
$$

Figure 9 shows the key dynamics of the economy under risk neutrality. For comparison, we also plot the responses under log-linear preferences, which was the baseline case. Figure 9 makes clear that risk aversion is a key parameter underlying the effect of endogenous choices. The responses when individuals are risk neutral are much closer to the responses under exogenous choices. This is intuitively obvious. The greater the risk aversion of the individual, the more she avoids market work when it entails the risk of exposure to infection. 
Figure 9: Role of Risk Aversion
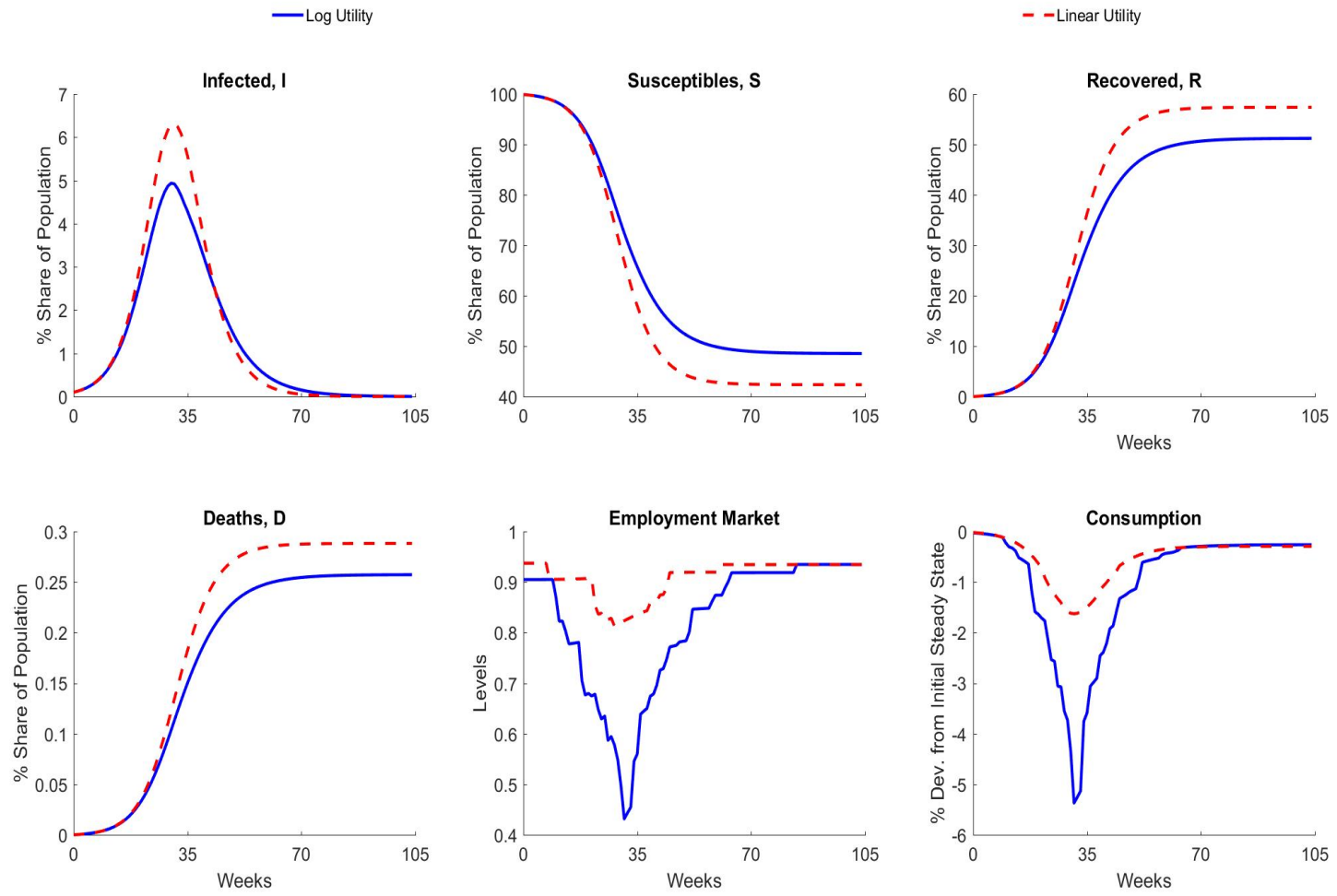

\subsection{Costs of infection}

The main focus of our work is on the salience of the individual's endogenous response to minimize the exposure risks posed by the pandemic. A key factor in assessing this risk is the impact of infections on earnings potential. In our model, there are two consequences of becoming infected. First, during the duration of the infection the individual's productivity declines by $1-\gamma_{I}^{m}$ percent for market work and $1-\gamma_{I}^{h}$ percent for home work. As $\gamma_{I}^{m}$ and $\gamma_{I}^{h}$ become smaller, the cost of infection becomes higher. The second consequence of infection is the risk of death, which occurs with probability $\pi_{D}$. The higher this probability the greater the expected cost of infection. We now explore the sensitivity of the responses to these two margins.

\subsubsection{Productivity of infected}

In our baseline simulations, we assumed that $\gamma_{I}^{m}=\gamma_{I}^{h}=0.8$. To examine the sensitivity of results to this parameter we compute the model responses to two different values: $\gamma_{I}^{m}=\gamma_{I}^{h}=0.9$ and $\gamma_{I}^{m}=\gamma_{I}^{h}=0.6$. Figure 10 shows the responses. The figure shows that a lower $\gamma_{I}$ lowers the 
Figure 10: Role of productivity when infected
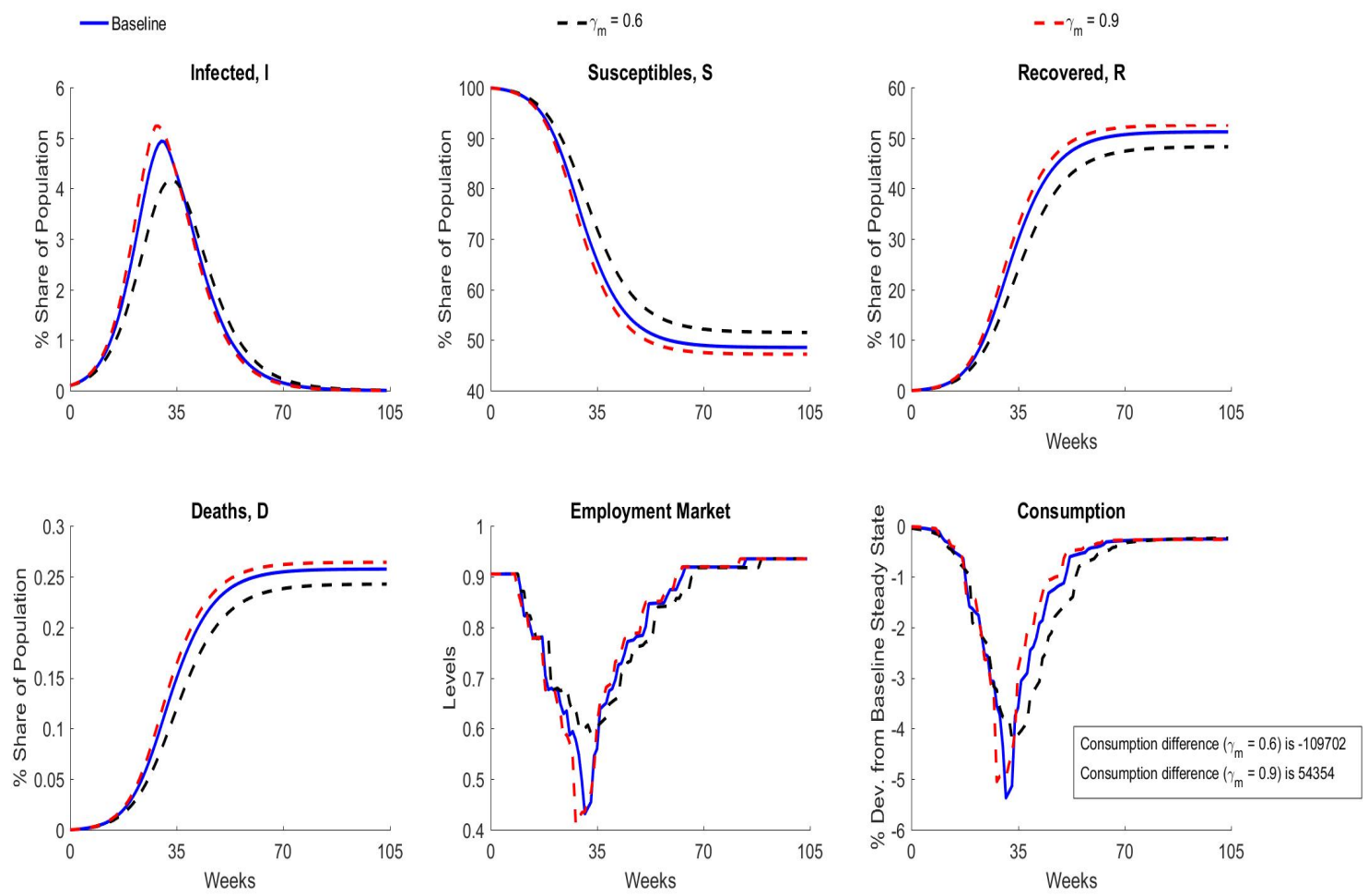

peak infection rate by a full percentage point while also delaying the peak. The infection rises more slowly and also declines less rapidly when $\gamma_{I}=0.6$ relative to the baseline case. As a result, the probability of infection perceived by susceptible individuals, $\pi^{m}$, rises and falls more slowly relative to the baseline. From Proposition 1 we know that more occupations switch to home work as the probability of infection rises. This can be seen in the slower decline and rise of market employment when $\gamma_{I}=0.6$ relative to the baseline of $\gamma_{I}=0.8$. This pattern is mirrored in the path of overall consumption which declines more slowly but also recovers more slowly over time.

The fact that the probability of infection falls more while the share of market employment declines less under a lower $\gamma_{I}$ might seem counterintuitive at first glance. The reason for this is the lower consumption of the infected. Since productivity of the infected is lower, their consumption levels are lower now relative to the baseline case. Since the probability of susceptibles becoming infected while consuming is proportional to the consumption of the infected, the overall infection probability declines as $\gamma_{I}$ falls. The lower risk exposure due to lower consumption of the infected also open up greater space for risk taking by susceptibles who respond by withdrawing less from risky market work. 


\subsubsection{Probability of death}

The baseline simulations assume a mortality rate of 0.5 percent which implies that $p i_{d}$ is 0.2 percent. We investigate the robustness of our results when $p i_{d}$ is 0.5 percent (mortality rate of 1.29 percent).

Figure 11: Role of probability of death
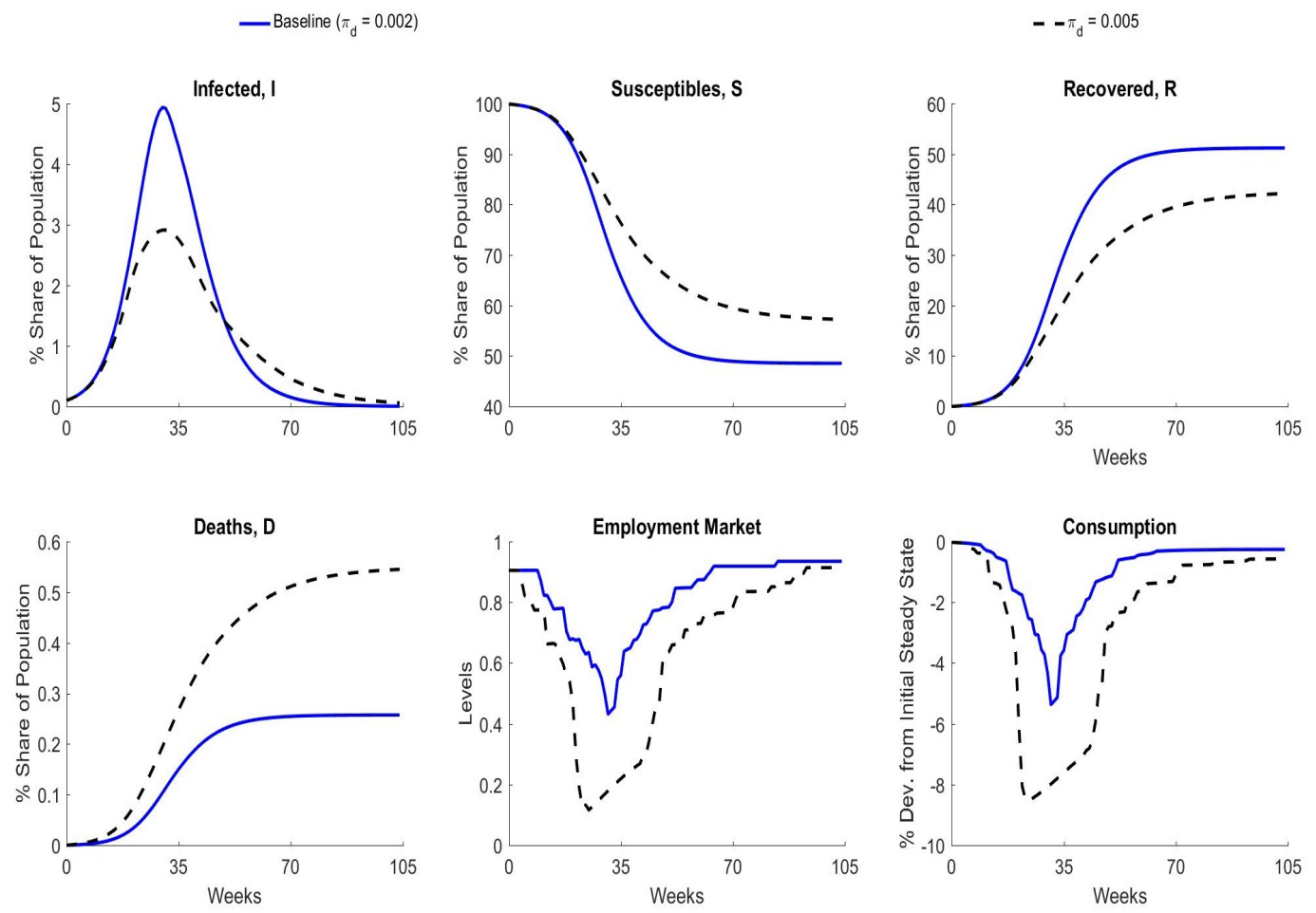

Figure 11 shows that a higher probability of death lowers the peak of infection rate by 2 percentage points compared to the baseline scenario. The death rate increases dramatically from 0.2 percent to 0.6 percent. Risk averse individuals respond to a higher probability of dying by further reducing market work. The share of individuals working in the market drop from 40 percent to 20 percent. But since now individuals with higher market productivity shift to working from home, the effect on consumption is now more pronounced. Consumption falls by 8 percent relative to steady state when the probability of death is higher compared to 5 percent. Thus, a higher mortality rate increases the economic costs of the pandemic. 


\subsection{Which Occupations stay home?}

Our model is calibrated to the BC labour force categorized according to the National Occupational Classification. We have described how occupations differ both according to the ease of work from home and the infection risk in the labour market. It is interesting to see what the model predicts for the distribution of market exits by occupation. Figure 12 lists the occupations that exit the market and for how long, in the baseline case and in response to the two lockdown scenarios, in the case of constant infection risk across occupations.

As one would expect, with constant risk, the occupations exiting the market are those whose opportunity cost is lower - particularly professional occupations with less customer or client physical interaction. We see also that the lockdown policies have a relatively minor impact upon the occupations that exit the market and the duration of exit.

Figure 12: Occupations exiting the market

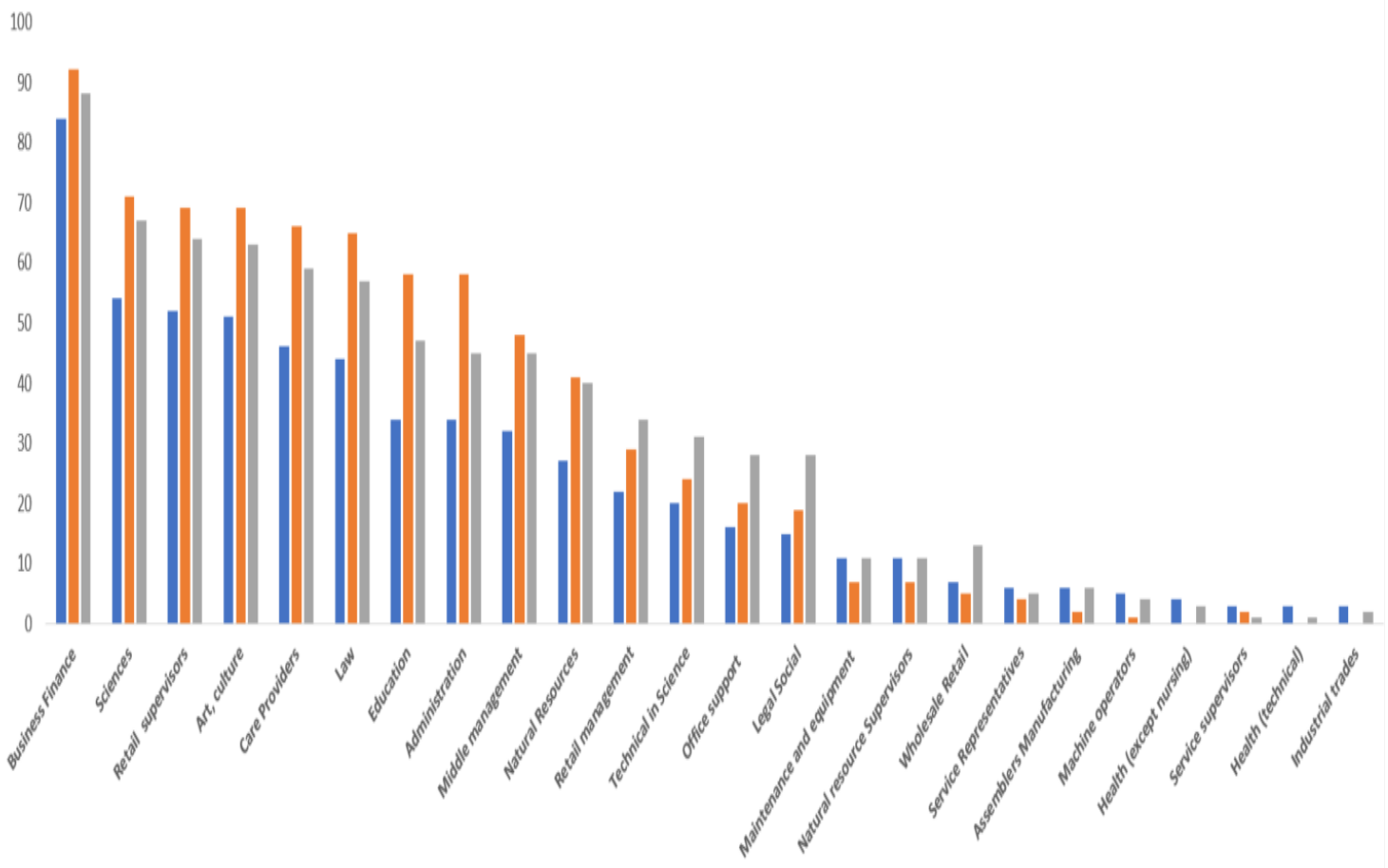

- Periods exited from market-work (baseline) $\quad$ - Tax 5\%, duration 36 weeks $\quad$ | Tax $12 \%$, duration 12 weeks

When we introduce occupation specific risk, Figure 13 shows that the type of occupations exiting the market changes quite considerably. Now individuals in 'risky' occupations such as health, retail, or front line protection choose to exit market work. But comparing Figures 12 and 13 it is still true 
that most of the time outside the market is accounted for by occupations with a lower opportunity cost of working from home. This holds both for the baseline case and for the lockdown experiments. This observation helps to explain the result in 8 above, where we saw that the model simulations under constant risk and occupational specific risk differ by only a minor degree.

Figure 13: Occupations exiting the market

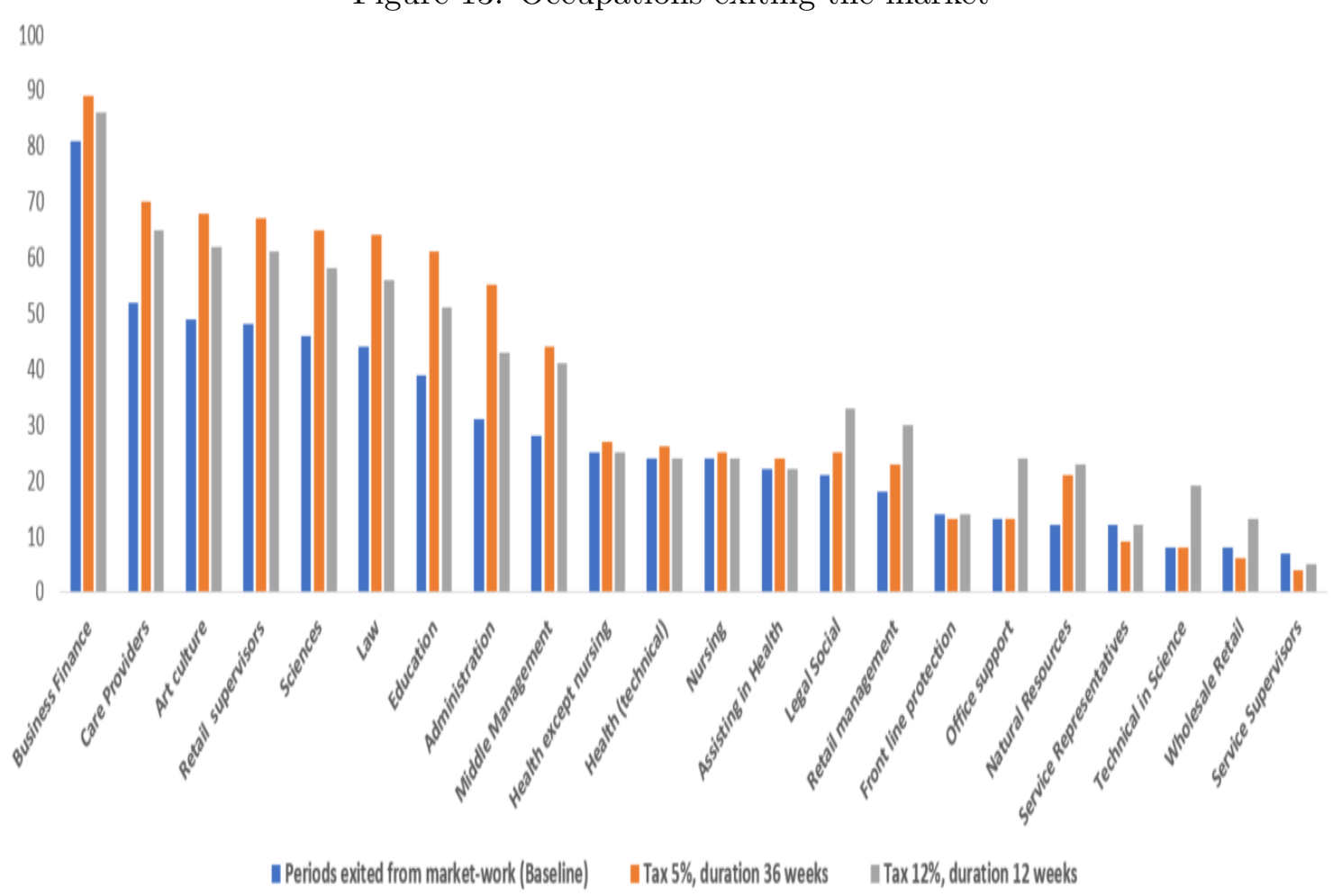

\section{Distributional Consequences of Pandemics}

The coronavirus epidemic has clearly disrupted economic life globally. Along with the aggregate contractionary effects, it has also had huge distributional consequences. Recent work by Chetty et al. (2020) uses credit card payments data to show that the overall consumption decline between January and June 17, 2020 was 8.9 percent. However, underneath this overall decline lies huge variation. This is shown in Panel (a) of Figure 14 which shows that during this period spending by consumers in zip codes with the top quartile of median income declined by 13.3 percent while spending by those in zip codes in the bottom quartile of incomes fell by a meagre 2.8 percent. More broadly, the figure shows that the spending in the richest zip codes declined the most on 
impact of the pandemic and has shown the slowest recovery. In contrast, spending fell the least in the poorest zip codes and recovered fastest. Panel (b) of Figure 14, following simulations from our

Figure 14: Consumption distribution: by quartiles

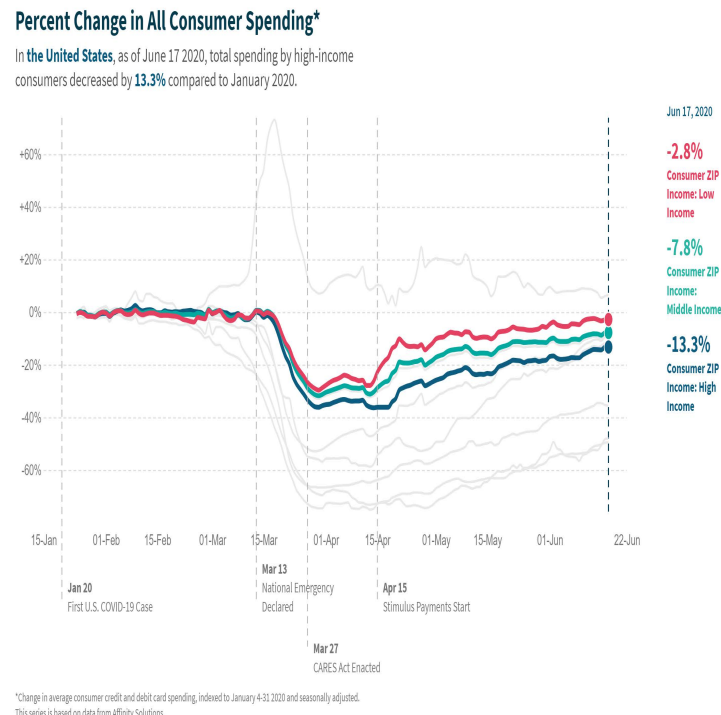

(a) Data

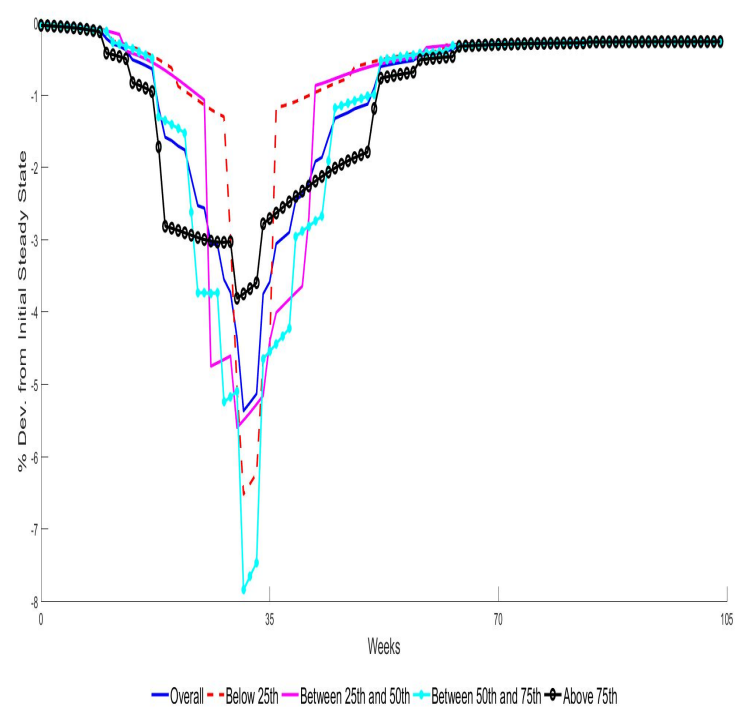

(b) Model

Note: The figure in panel (a) is from the Opportunity Insights Economic Tracker. Work using this data can be found in Chetty et al. (2020).

model shows the model counterparts consumption responses by quartile for the baseline simulation. These responses are generated from the version of the model without any lockdowns, or for $\tau_{m}=0$.

A few features of panel (b) are noteworthy. First, as in the data, the consumption of the lowest income quartile in the model recovers the fastest while the consumption recovery of the top quartile is the slowest. Second, up to about 16 weeks after the start of the infection, the consumption declines are positively ordered by the income quartiles: the largest declines are for the richest quartiles followed by the 3 quartile, 2 nd and poorest quartiles. This also fits the qualitative features in panel (a). We should note that this is even without accounting for the the transfer payments (made both in Canada and the US) that were directed at the relatively poorer income groups.

Panel (b) of Figure 14 also suggests that even though the lowest income groups have held up their consumption levels up until now, there may be significant consumption declines ahead for this group as their incomes decline due to more infections that are induced by their inability to substitute into home production. This is due to the fact that the lower income groups are mostly 
in occupations where the home wage premium is negative and large.

\section{Conclusion}

We have developed a simple macro model which, in conjunction with a standard SIR model, gives to rise to endogenous cycles in both infections and output. The model has the standard interaction between economic and infection outcomes. Economic market activity increases infection risks while lockdowns reduce infections at the cost of deeper recession. The key innovation of our model is that it focuses on occupations and the endogenous choice by individuals whether to work in the market or from home.

The quantitative results from the model calibrated to Canadian data from the 2016 census suggest that the endogenous response of private agents to market risk can be significant with the peak infection rate being 1 percentage point lower than when private supply of market work is exogenously given. Correspondingly, the output loss at the deepest point (the trough) is 4 percentage points greater under the endogenous choice case.

Our results have a key policy implication. Since individuals are willing to pay to insure themselves against infection risk by withdrawing from the market, opening up the economy may not lead to a sharp recovery. Until people develop confidence about the safety of market activity, they will continue to self-isolate. While self-isolation may not be an option for people in occupations that are intensive in social interactions, their returns from market activity are often dependent on the market consumption activity by others. If a significant share of people withdraw from consuming in the market, upstream suppliers of these services and goods will suffer income and job losses as a result. Our results suggest that this effect can be quantitatively high. Dealing with this confidence problem may involve spending on intensive testing rather than direct fiscal infusions into the economy.

The model also provided interesting insights into the effects of lockdowns. We found that intense but shorter lockdowns do not materially change the infection dynamics or the cumulated number of deaths except for marginally postponing the peak of the infection. Longer and possibly less intensive lockdowns on the other hand may be more effective in lowering the infection peak. However, they have the opposite effects on the economic costs of the pandemic. The shorter but more intensive 
lockdown has lower cumulated output costs relative to the longer but milder lockdown.

\section{References}

Acemoglu, D., V. Chernozhukov, I. Werning, and M. Whinston (2020). A Multi-Risk SIR Model with Optimally Targeted Lockdown. NBER Working Paper No. 27102.

Alvarez, F. E., D. Argente, and F. Lippi (2020). A Simple Planning Problem for COVID-19 Lockdown. NBER Working Paper No. 26981.

Atkeson, A. (2020). What Will Be the Economic Impact of COVID-19 in the US? Rough Estimates of Disease Scenarios. NBER Working Paper 26867.

Bodenstein, M., G. Corsetti, and L. Guerrieri (2020). Social distancing and supply disruptions in a pandemic. Covid Economics - Vetted and Real-Time Papers (19), 1-52.

Brodeur, A., D. Gray, A. I. Suraiya, and J. Bhuiyan (2020). A Literature Review of the Economics of COVID-19. IZA DP No. 13411.

Chetty, R., J. N. Friedman, N. Hendren, M. Stepner, and The Opportunity Insights Team (2020). How Did COVID-19 and Stabilization Policies Affect Spending and Employment? A New RealTime Economic Tracker Based on Private Sector Data. NBER Working Paper No. 27431.

Dingel, J. and B. Neiman (2020). How Many Jobs Can be Done at Home? NBER Working Paper 26948.

Eichenbaum, M., S. Rebelo, and M. Trabandt (2020). The Macroeconomics of Epidemics. NBER Working Paper 26882.

Ferguson, N. M., D. A. T. Cummings, C. Fraser, J. C. Cajka, P. C. Cooley, and D. S. Burke (2006). Strategies for mitigating an influenza pandemic. Nature 442(7101), 448-452.

Goolsbee, A. and C. Syverson (2020). Fear, Lockdown, and Diversion: Comparing Drivers of Pandemic Economic Decline 2020. NBER Working Paper No. 27432.

Hur, S. and M. Jenuwine (2020). Lessons on the Economics of Pandemics from Recent Research. Economic Commentary (Federal Reserve Bank of Cleveland) (2020-11), 1-7. 
Jones, C., T. Philippon, and V. Venkateswaran (2020). Optimal Mitigation Policies in a Pandemic: Social Distancing and Working from Home. NBER Working Paper 26984.

Krueger, D., H. Uhlig, and T. Xie (2020). Macroeconomic Dynamics and Reallocation in an Epidemic. NBER Working Paper No. 27047.

Mandavilli, A. (2020). Actual Coronavirus Infections Vastly Undercounted, C.D.C. Data Shows.

Regus (2017). The workplace revolution. Technical report. 